(1)

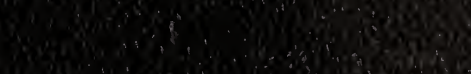

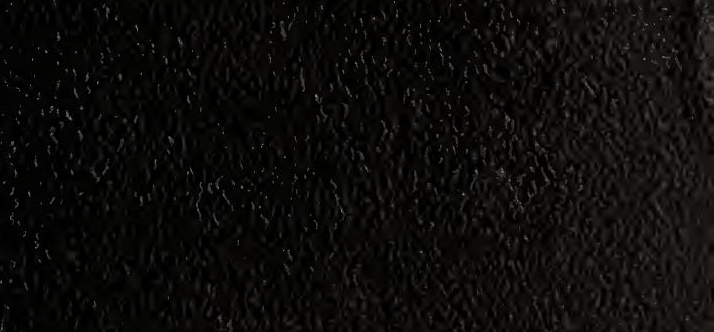
4.

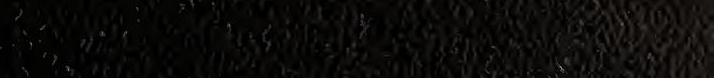

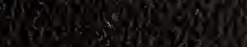
De 6ens

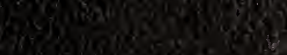
我. 180.5

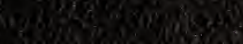

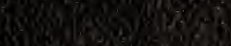

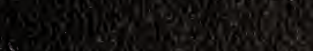
3.

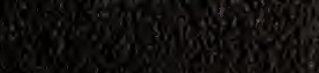
3. ayoriss

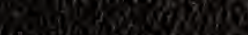
3050 s.

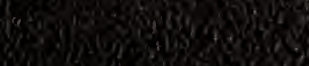
oxing

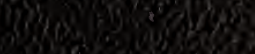
ing (3). Whasiongente 


\section{nR59118}

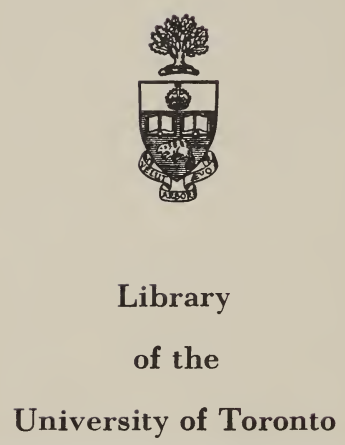




\title{
NOTES ON NETS;
}

OR,

\author{
THE QUINCUNX PRACTICALLY CONSIDERED.
}

TO WHICH ARE ADDED

MISCELLANEOUS MEMORANDA.

BY

The Hon. and Rev. Charles BathURST, L.L.D.

LATE FELLOW OF ALL SOULS' COLLEGE, OXFORD.

Who can but magnifie the power of Decussation!-Sir Thomas Brown.

It is esteemed a kind of dishonour unto Learning, to descend to inquiry or meditation upon matters mechanical, except they be such as may be thought secrets, rarities, and special subtilties; which humour of vain and supercilious arrogancy is justly derided in Plato.

LoRD BACoN's Advancement of Learning, Book II.

\section{LONDON :}

JOHN VAN VOORST, I, PATERNOSTER ROW.

THOMAS PHILIP BAILY, CIRENCESTER;

VAN DER MEER, AND VERBRUGGEN, ROTTERDAM ; AND TO BE HAD OF ALL BOOKSELLERS. 



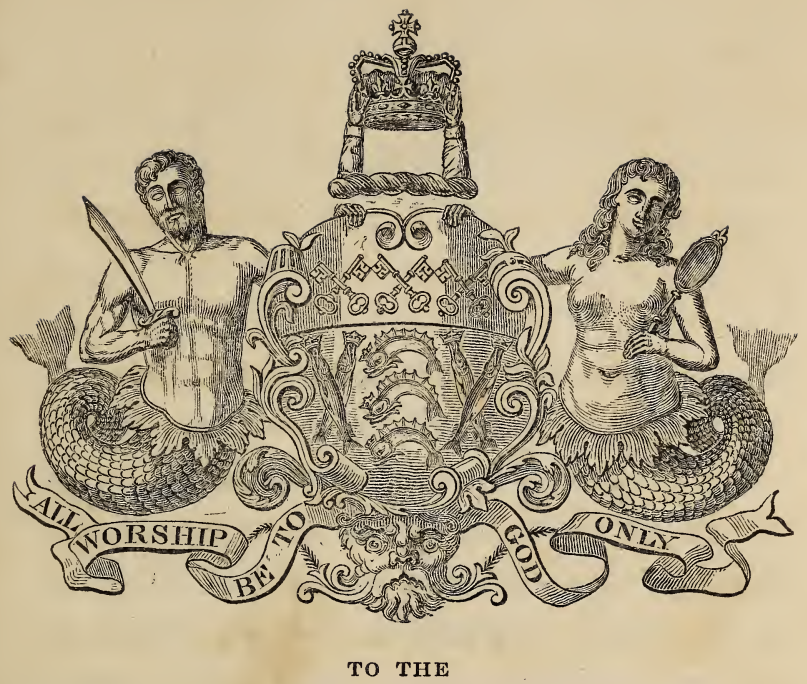

\section{WORSHIPFUL COMPANY OF FISHMONGERS,}

This yolume

IS RESPECTFULLY DEDICATED

BY

THE AUTHOR;

WITH

THE MOST SINCERE WISHES THAT THEIR SPLENDID

\section{HALL AND ITS OCCUPANTS}

MAX EVER CONTINUE TO RANK AS THEY NOW DO, AMONG THE MOST

DISTINGUISHED ORNAMENTS

oF

The Ancient झport and City of zlondon. 


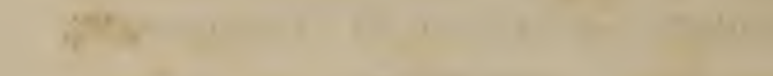

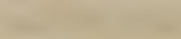

,

(1)

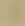

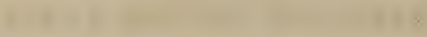

,

$$
\begin{aligned}
& \text { i } \\
& x^{2}
\end{aligned}
$$

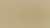




\section{PREFACE.}

IT has often been said, that for a nation whose people in general display an almost unrivalled spirit of enterprise, and the most indefatigable industry, England shews an extraordinary degree of apathy in one branch of trade, viz. her Fisheries; which, it is urged, is the more unaccountable when we consider, that the natural advantages enjoyed by an Island are so superior to those possessed by any country forming only part of a Continent, as that success in such an undertaking is almost certain.

Again, we hear it often objected that the British Legislature does not afford sufficient assistance to our Fishermen, and is backward in protecting them as they ought to be protected, from nuisances on the rivers and from the aggression of foreigners on the seas. Not having the opportunity of gaining such information on these matters as would justify 
vi.

me in venturing an opinion, I abstain from offering any here, neither do I think it pertinent to the object I have in view, to moot the question as to how far any revision or improvement of the existing statutes, or the framing of new regulations, might conduce to render our Fishing Fleets better seminaries for the Royal Navy and the British Merchant Service, those noble defenders of our shores, those dauntless guardians of our commerce, those enterprising promoters of our geographical knowledge.

I leave it also to others to say, whether a stricter system of police, the widening and deepening of small streams, or encouraging the introduction of many kinds of fish at present unknown in this country, might be the means of diminishing the crime of poaching,- that prolific mother of other vices,of increasing an important article of food, and of procuring more employment for the poor, by fostering and extending the Trade of Inland Fishing.

I enter not, I say, upon these questions ; but leave them to others who are more 
qualified to discuss subjects relating to national policy; though I trust that none can be found more desirous than myself to see the labours, the ingenuity, and the enterprise of our countrymen protected, rewarded, and acknowledged by a grateful Nation. None, I believe, can be more anxious than I am, to see the English peasantry encouraged, by salutary enactments and the exertions of their wealthier brethren, to better their condition both moral and physical, and stimulated to observe habits of industry and prudence, and to avoid those pestilential haunts of vice and idleness : the rural Beer-shop and metropolitan Gin-palace. Nothing perhaps can conduce more to this happy end than daily putting greater facilities in their way for quitting such dissipated and injurious paths, in the shape of active employment, and in the establishment of those excellent institutions, the Self-supporting Dispensaries and Benefit Clubs. Nay, I find that my very eagerness on this head has led me to wander from my subject; I must therefore repeat, that it is not the b 2 
object of this little work to enter into the discussion of those weighty matters alluded to; I venture no opinion upon such points ; but of one thing I am certain ; that in general very little is known of the mechanism of those engines which procure for us our supply of fish and many other domestic comforts and conveniences, but which can only be made by persons skilled in the Art of Reticulation.

Every branch of art or manufacture has had its guide, or its catechism, or its alphabet, and so on; but the art of netting seems, by some accident, to have entirely escaped the notice of the press; although, in truth, it is the art which furnishes us with much wholesome food through its immediate instrumentality, urges men to industry, and can be practised without any very great outlay of capital to the maker.

It is strange too, that when there is such an eagerness, as there appears to be in these days, amongst persons of all ranks " rerum cognoscere causas," that some inquiry should not be made into the manufacture of 
our Nets ; an inquiry, which, however it may be condemned as puerile by the ignorant, sneered at by the fastidious, and ridiculed by the idle, cannot fail of being useful to the mechanic, interesting to the naturalist, and entertaining to the general observer. "The " truth is,"- says a noble and learned philosopher,- " they be not the highest instances " that give the securest information, as may "be well expressed in the tale so common, " of the philosopher, that while he gazed " upwards to the stars fell into the water; " for if he had looked down he might have " seen the stars in the water, but looking " aloft, he could not see the water in the "stars. So it cometh often to pass, that " mean and small things discover great, " better than great can discover the small." Science has indeed enabled man to soar for a few hours in the air to an height exceeding the flight of the most powerful bird. Yet the aeronaut cannot guide his balloon and chase the tenants of the air in their natural element ; but the fowler spreads his net and takes them captive; and can, 
by this device, transport them alive to other and distant abodes ; there to " increase and multiply" where they were formerly unknown.

Science has again put a powerful and effective weapon into man's hand, by which, without risk of danger to himself and without quitting terra firma, he is able, by a slight touch of the finger, to bring down the feathered tribes from their lofty eminence; but the smaller birds, whether required for the cabinet of the ornithologist, or the table of " the way-faring man," are rendered almost useless either for the one purpose or the other, by the shattering effects of the shot; surely an ingeniously contrived net will then do good service, being free from all such objections, yet effectual in its operations.

Man can at the utmost dive into the deep but for a short time, and can take but a very circumscribed range beneath the waters; but the netmaker has enabled him to possess himself, with facility, of every kind of fish, though these inhabit an element so contrary 
to his own nature, so speedily destructive of his own life. Again,

The arrow of the Indian, or the envied gun of the European, may arrest the flight of the swiftest wing, or stop the speed of the nimblest foot; but they are useless against the finny tribe; these would seem at first to be separated from their human pursuers by an impenetrable barrier; they can in a moment escape our sight, defy our attempts at grasping them, and leave us far behind on the shore or bank, totally unable to pursue them. Our gun-powder, our steam, our diving-bell, are all of no avail, powerful as they are, and mighty in their effects, elsewhere. But the gulf is not impassable nevertheless. By industry, and by science practically applied to art, man has contrived to invade the haunts of the inhabitants of the ocean and the stream; by Reticulation he is enabled to supply an almost inexhaustible stock of provision for home consumption, and to carry on an extensive Commerce with other Nations.

It is then, I conceive, very interesting, 
and, I may add, useful, to inquire into the mode by which inan has thus triumphed over impediments of no slight difficulty, and has succeeded, by ingenuity and dexterity, to render that a source of profit and employment, which would otherwise have afforded only amusement to the Angler, and an occasional and precarious supply to his table. Into this it is the object of these few Notes to inquire.

If, in addition to this, I can shew that in all our occupations, we may trace the " finger of GOD,". directing the present happiness, and pointing to the eternal welfare of His creatures-if in these Notes and Memoranda I can, in the smallest degree, contribute to the promotion of GOD's glory, or mitigate the rancour of party-spirit, by leading men-nay, if it be but one man-to occupy his thoughts on higher and holier, on more soothing and agreeable objects ; and, finally, if I can be the humble instrument of saving but one poor brute from unnecessary pain and toil-I shall, indeed have, in the remembrance of such an effect, 
more than my reward for any anxiety I may now feel lest, peradventure, though intending well, I may be acused by more able and scientific persons of presumption in sending forth these pages into the world in such a meagre shape and incomplete style.

I believe there are some individuals who will consider that it is a sign of great weakness, if not of positive wickedness, in me, to dare to anticipate such important and happy results as those above alluded to from "these low delights and poor maniples." To objectors of this sort, I can make only one answer, viz. that, conscious to myself of integrity of purpose, but at the same time deeply feeling and truly deploring my insufficiency-" and who is sufficient for these things ?"-I leave, on this as on all occasions, the issue of my imperfect endeavours to act up to the character of the "faithful minister of the LORD," unto the guidance of Him who is able to "strenghten the weak hands," and who can, with the humblest instruments, work that great work of Divine Mercy-even the Salvation of the Souls of 
xiv. PREFACE.

men, as easily, as with the use of the mere dust and clay beneath His feet, He healed the bodily ailments of those who came to Him for relief! "With man," indeed, " this is impossible, but, with GOD, all things are possible."

$$
\text { C. B. }
$$


The Author begs to express his grateful thanks to Messrs. Breach \& Sons, of Hastings; Henry Clifton, Esq. of Whittington, near Worcester; John Clifton, Esq. of Worcester; Henry Delme', Esq. of Cams, Fareham. Benjamin Edgington, Esq. of Duke Street, Southwark; John Fane, Esq. of Wormesley Park, Oxon; Vice Admiral Sir 'Thomas M. Hardy, G.C.B., Bart. \&c. \&c. Governor of the Royal Hospital Greenwich; Edward Jesse, Esq. F.L.S. Surveyor of Her Majesty's Parks, of Hampton Court; Mr. Kirtland, of the Ashmolean Museum, Oxford; The Rev. Henry A. Pye, M.A. of Cirencester; and William Yarrell, Esq. F.L.S. and V.P.Z.S., of Ryder Street, London; for their kindness in procuring him specimens of Nets for inspection. Also, to Mr. T. P. Baily, of the Columbian Press, Cirencester; Mr. Johnson, Engraver, of Cheltenham; and Mr. VAN Voorst, Publisher, of London; for their assistance in their several departments. 


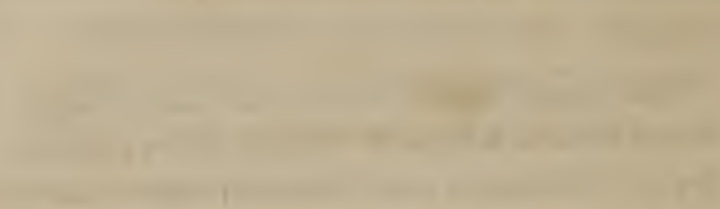

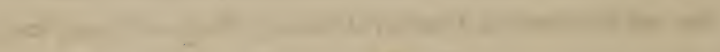
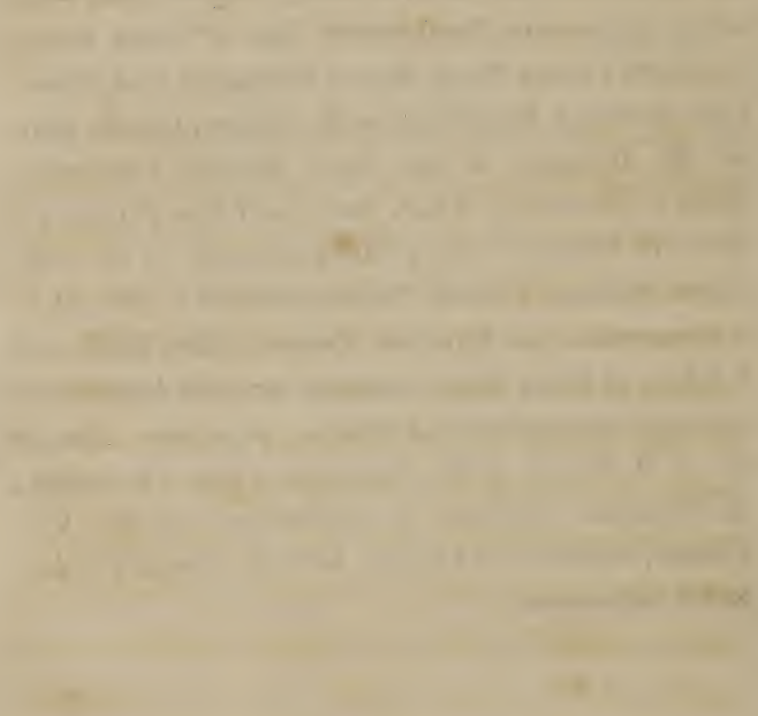


\section{NOTES ON NETS.}

\section{INTRODUCTION.}

Iter est non tritâ auctoribus viâ nec dubitamus multa esse quæ et nos præterierint.-PLINY.

Doctor Samuel Johnson expressed his opinion of Netting,* that " next to mere idleness, " it ought to be reckoned in the scale of insignifi"cance;" whether he came to this decision, so unfavourable to that species of employment, in consequence of his avowed inability to practice the art, or from an unwillingness to consider the matter more gravely, I do not pretend to decide; nor is it my intention to argue so knotty a point with that great literary Goliath; I should be as justly chargeable with reckless presumption, as he would be who would make a net of gossamer, wherewithal to contest the paths of the sea with the mighty leviathan of the deep. But let not

* Dr. Johnson predicated this of knotting, but he defines knotting as netting. 
those arch-enemies to reticulation-the Anglersbe too hasty in triumphing over us advocates of the spool and needle, even though such high authority can be quoted against us; for the same "illustrious friend" of Boswell defined the art of Angling in no very courteous terms, which I shall not repeat, and that too he said of the Angler in his glory, and at the moment of success. DR. Johnson was no angler, and therefore had imbibed some prejudice against that occupation, as he had against netting. Whilst the knights of the rod and line can appeal against all the grave and unfair charges, which have been brought against them, of cruelty and folly, \&c. \&c. to the works of an IzaAk Walton, a Cotton, a DAvr, or a JEsse, in support of their favourite and rational pursuit, I hope to shelter my art from unmerited obloquy by referring to the labours of the scientific DUHAMEL, who has written at length on the Mode of Netting, as practised in France for Fishing.

Many persons, I believe, consider a net simply as a shapeless mass of meshes, forming a certain quantity of "dead netting," as that is technically called which consists of plain work in regular 
rows; few ever take notice of the various shapes and contrivances exhibited in nets, with which the workman must be familiar, so as to be able to modify, apply, or alter them, as occasion may require. One department of the netmaker's labours, and that which is doubtless the most extensive and important, will serve to shew, perhaps, that this art is not so insignificant and beneath the notice of the general reader, as some are apt at first to suppose. Let any one pay a visit to Billingsgate or Hungerford Market, at the full tide of business, and there he will soon perceive that it required no few cwts. of netting to bring ashore that enormous supply of fish laid out before him. Let him go on to Hastings-it is the fashion to go to Hastings now-and there he will find the beach completely carpeted with nets of different shapes and sizes lying to dry; or trawls, hanging from the masts of seventy or more vessels and waving in the breeze, may be seen torn and wounded, after being engaged in their perilous voyages in search of that great article of commerce which adorns the shops of our Groves and Goters at the west end. The nets alone at Hastings cost the owners $£ 3000$ per annum. The 
Mackerel nets extend two miles in length, and those for Herrings one mile. Their twine is procured from Bridport, and other distant places; added to this, there are boats, and wages, and losses, and wear and tear, to be taken into the account; so that when we look into the matter, we shall find there is some ado to get a dish of fish. Then let our supposed traveller go along the banks of the rivers-if it is in summer, he had better get a net for his horses, by the by, to keep the flies from troubling and teasing the poor fellows-and there he will find no mean array of reticular devices, used in furnishing the tables of the wealthier classes with the more highly prized, and the cottages of the poorer ranks with the less esteemed, produce of the waters. Then again, in his journey he may chance to see fowling nets, and rabbit nets, and nets for aviaries, and nets of every shape, size, grade, and texture. It is easier then to deride an employment than to disprove its utility and importance-it is easier to call things by hard names than to make them-but, whether it be altogether wise to do so, is another question.

I remember an old gentleman-a very goodhumoured old gentleman too-who often used to 
call Sir Joseph BANkes " that butterfly hunter," in the utmost contempt for Entomology-not for the distinguished individual, whose amenity of manners and kindliness of disposition rendered him justly respected by both old and young, even by those who could not appreciate his philosophical pursuits.

But to return to the more homely subject of Nets. The French Sçavans, as has been hinted already, have by no means deemed the art of netmaking, as far as fishing is concerned, beneath their attention; and one of their most scientific writers has exercised his pen in furnishing descriptions of the general structure of fishing nets, and in other remarks on this interesting subject. There is no English work, however, as far as I know and believe, which treats of this matter farther than a mere cursory notice or two upon the shape and use of nets; I have, therefore, endeavoured to supply this deficiency, to a certain degree, by putting together a few Practical Instructions and Remarks on the Form and Structure of various kinds of Nets, such as are most commonly used in our Sea and River Fisheries in England, as well as those made for other purposes. 
I have added to these hints a few Miscellaneous Memoranda on other subjects, which I happened to find recorded in the pages of my Note-Book. As to style, I pretend to nothing more than a rambling one, my book being little else than patch-work, the materials of which have been collected at odd times, and in rambles along the beach and bank; and my professional avocations not allowing me leisure to put them into more bookish order. Although, then, these hints are written without any idea of furnishing a complete work on the art of decussation, but only as a guide to beginners, I am by no means ignorant of the many faults and failings which, even as such, it must contain, and know myself to be ill versed in author-craft; I nevertheless trust that this insignificant, yet I hope I may add, harmless, volume, will not prove entirely uninteresting, and that my readers will not be severe to mark those errors and deficiencies "quas aut incuria fudit, aut humana parum cavit natura." 


\section{Note I.}

"Quid mare non novit quis nescit tellus ?"

Ovid.

of the Antiquity and General Adoption of Nets.

Aт a Meeting of the Entomological Society of London, last year, a paper was read by the Secretary, on the exclusion of the house-fly from dwellings. The mode adopted was a net of different coloured meshes, about three-quarters of an inch square, and which, when placed against a window, was found quite effectual in excluding the visits of these troublesome insects from the inside of the room. The same experiment was tried with meshes made of the finest black thread, one inch and a quarter square, which proved to be equally effectual. The approach of wasps was also prevented by the above mode, very few finding their way within the boundary. This was accounted for by an optical illusion in the eyes of the insect. 
That net-work is a defence against the intrusions of some insects, and those particularly of the Dipterous Order, as the house-fly is, was known at least 2280 years previously to the paper abovementioned being read before the Entomological Society in London; Herodotus having, in the year 445 B.C. read his nine celebrated books before the Sçavans of Greece, at the Olympic Games, in which the following passage occurs : "The Egyptians are provided with a remedy " against gnats, $*$ of which there are a surprising " number. As the wind will not suffer these " insects to rise from the ground, the inhabitants " of the higher part of the country usually sleep " in turrets. They who live in the marshy grounds " use this substitute: each person has a net, with

* " The land of Egypt being annually overflowed, was, " on that account, pestered with swarms of flies. They " were so troublesome, that the people, as Herodotus " assures us, were, in many places, forced to lie on the tops " of their houses, which were flat, where they were obliged " to cover themselves with net-work, called by Juvenal "Conopeum. This is described by the Scholiast as 'linum " tenissimis maculis nectum,' a knitting together of line “ into very fine meshes."-Bryant.

(See Beloe's Herod. vol. 1. p. 438.) 
"which they fish by day, and which they render " useful by night; they cover their beds with their " nets, and sleep securely beneath them. If they "slept in their common habits, or under linen, " the gnats would not fail to torment them, which " they do not even attempt through a net."

Our English word canopy, it is well known, is derived from the "konopeion," or gnat net, used in the East, and referred to by authors both sacred and heathen.

In the Musèe Royale, at the Hague, there is a specimen of a fishing net used on the coast of Guinea; "Un filet fait de feuilles d'ananas de la côte de Guinée." The meshes are not knotted tight together, but the entire net is made of threads interlacing with each other, and moving as they are extended, either more or less, in any direction freely over each other. A Chinese hammock, which I saw at Hastings, made from twine of bass, was constructed much in the same manner. The loops rode or moved one over the other, and were interlaced, but were made of different lengths, so as to form a pattern somewhat resembling the wire-work of an English fire-guard for grates, only there were no knots or ties at the points of inter- 
section. The loops kept their shape owing to the elasticity and stiffness of the material of which they were made. I have somewhere seen some South Sea Islanders' nets for fishing, with meshes interlaced and not knotted together in our way. Some nets, however, from the South Seas, which I shall have occasion to mention more particularly hereafter, now in the Ashmolean Museum, Oxford, are made with knots precisely like our nets.

Finally, a Christian will readily call to mind the circumstance of our LORD likening the kingdom of Heaven to a Net. (See Matt. xiii.47.) And, if I may be allowed the expression, the net has from that time been invested with somewhat of a sacred character. Let not the idle and thoughtless sneer at this remark, however much he may be inclined to think lightly of him who has ventured to make it, in the hope of leading the inconsiderate to think seriously and soberly, even through a bye-path. And I trust that no religious person will consider that I have introduced sacred things amidst worldly occupations and amusements, at an unseasonable time, or in an indecorous manner. "Whatsoever ye do, do all to the glory of GOD." Our LORD took constant occasion to enforce his doctrines 
and precepts on the minds of his hearers, by calling their attention to trifling things and events, which things and events, however trifling they were when abstractedly. considered, have been endued with great importance and dignity, because spoken of by Him who "spake as never man spake," and used by Him as instruments in performing the great work which His Heavenly FATHER sent Him to work. It was, doubtless, intended by our SAVIOUR, that all of us, and not only those who immediately accompanied Him at the time, should turn " the things that are made," and which daily surround us, to good account, by rendering them subservient to our eternal benefit and spiritual instruction, as well as conducive to our present comfort and worldly advantage. Far be it from me to advise an ill-timed or unguarded use of scriptural allusions or language, by advancing such topics on every and all occasions, before persons of all tempers and dispositions; for to do this, is to expose the object of our veneration and worship to the insults of the licentious, the blasphemies of the fool, and the ribaldry of the buffoon. It would be idle to talk of the "Pearl of great price" to a swinish herd of drunkards, in 
the midst of their revelry ; or of that " treasure," "whose merchandise is better than the merchan" dise of silver, and the gain thereof than fine "gold," to a man "who knoweth not the price "thereof." A discreet selection of "times and seasons" for speaking of serious matters, should always be kept in view, and a demeanour equally remote from gloominess as from levity should characterize our conversation; for, in truth, the most useful tools, if used in a careless manner, or by heavy or awkward hands, or in a stage of the work not suited to them, or to a purpose for which they were never intended, become, through misapplication, inefficient, dangerous, and destructive instruments. 


\section{Note II.}

Proferet in lucem speciosa vocabula rerum.-HoR.

Of the Tools and Terms mostly used by Netmakers.

These are very few, but are frequently misapplied and made use of ambiguously.

To Breed a net is to make, or net, a net.

Dead Netting, is a piece of work made without any widenings or contractions.

False Loops, also called Quarterings, are Loops or Quincunxes, inserted in any given row, by which the number of loops in the work is increased.

Meshes are the squares formed by netting row after row. The word is often incorrectly used for the half squares formed by one row. Some persons also call the Spool or Mesh-Pin, or that on which the meshes are made, a Mesh; but this is incorrect and inconvenient.

$A$ Needle is the instrument used for holding the thread or twine to be netted. 
A Spool is the round or flat piece of wood upon which the meshes are formed; the size of the spool determining the size of the meshes. Each time that a loop or quincunx is made, half a mesh is completed. The shapes, both of needles and spools, will be noticed hereafter.

Stole (i.e. Stolen) Meshes are so called when two loops are taken up at once on the needle, thereby diminishing the net at the parts required.

Taught (tight). The string or twine is pulled "taught" when a loop is made.

A Quincunx is one loop, or half mesh. The Roman V is a sign for five-five ounces amongst five of other things - hence the Latin word quincunx, or measure of five ounces, is given to the half mesh, because it resembles a $\mathrm{V}$, when the net is pulled downwards; and the whole mesh is a "Quincuncial Lozenge." For a farther account of which, see Sir Thomas Brown's Garden of Cyrus, or the Quincuncial Lozenge, or Net-work Plantations of the Ancients Artificially, Naturally, and Mystically Considered.

A pair of good stout Scissors and a Knife are also indispensable.

The French netmakers recommend Gauges for 
measuring the size of the meshes; and a tool called a Valet for keeping a net stretched out at any particular part whilst working at it; I have never used them nor required them, neither have I ever seen them used by others.

Of Needles there are two kinds-those made alike at each end, with open forks, as in fig. I; and those made with an eye $\mathrm{E}$, and tongue $\mathrm{T}$, as in fig. 2. In both needles the twine is wound on them nearly in the same manner, viz. by passing it alternately between the fork at each end in the first case, or between the fork at the lower end and round the tongue at the upper end, in the second case; so that the turns of the string may lie parallel to the length of the needle, and be kept on by the tongue and fork. The Needle No. 2. is preferable, both for making and mending nets, inasmuch as it is not so liable to get hitched into the adjoining meshes in working; but some netters prefer the other kind, as being capable of holding more twine in proportion to their size; in a few instances, as in tucks of Casting Nets, this may be a matter worthy of attention. A very short needle, say four inches long, should be kept, among a set of about six others, of different 
sizes for general use, solely for mending injured nets with.

Spools, of various sizes as to circumference, should also be provided. In the Wallings of Trammels a very large spool is required, which must be made flat and not round. Duhamel describes those used by the French as follows :"Si les mailles sont grandes, les moules cylindri"ques seroient trop gros pour être tenus entre "les doigts, c'est pourquoi on les fait avec une " petite planche qui a aux bouts (a. b. fig. $3 \& 4$ ) " un ou deux talons pour empêcher le fil de couler "sur le bout de ces moules; car le fil qui doit faire "la maille, envelope ici le moule suivant la "longueur, ainsi que l'indiquent les lignes ponc"tuées. Ces Moules ne doivent avoir que 3 à 4 "lignes d'épaisseur, et être faits d'un bois fort "leger; parce qu'il faut les tenir entre le pouce et "le doigt index de la main gauche."

Amongst many other marks of kindness which I have received from Arthur Annesley, Esq. of Bletchingdon Park, and which I hope I may ever feel truly grateful for, and anxious to acknowledge, was a spool for large meshes, infinitely superior to, and more handy than, that of 
Duhamel's describing. The spool in question was, I believe, also invented, as well as given to me, by the donor. (See fig. 5.) It consists of a flat piece of wood, of any given width, of stout wood, so as not to warp, with a portion cut away at one end, to admit the finger and thumb of the left hand to grasp it conveniently. The twine, in netting, embraces the spool across the width, in the direction of the dotted line. Large meshes may be made on small spools, by giving the twine two or more turns round them, as occasion may require.

A Rean is a cord or thread of stout twine, proceeding from the extremity of a piece of netting, whereby it is fastened to some support; presenting, in its relation to, and action upon, the netting, some analogy to that which a tendon bears to a muscle in the Animal Economy.

"If mankind," says Lord BAcon, "were "desirous to search after useful things, they " ought attentively, minutely, and on set purpose, " to view the workmanship and particular opera"tions of nature, and be continually examining " and casting about which of them may be trans- 
"ferred to arts ; for Nature is the Mirror of Art." There are many instances of Arts copied from Nature, in M. Surell's Treatise de la Science Universelle. 


\section{Note III.}

\section{Incipias conferre manum.-VIRG.}

\section{How to Make a Loop, and Meshes.}

Is order to render the hints which follow of any use, we must first of all consider the manipulation of the spool and needle, and practise the manual exercise of plain netting. A careful examination of the fig. 6 will soon put the beginner in possession of the "modus operandi ;" and the knowledge of this manœuvre being once obtained, is not easily forgotten, and little difficulty remains to be mastered afterwards. I must, however, before I proceed, acknowledge that I am mainly indebted to the columns of the Saturday Magazine for the directions contained in this Note; I give them in this place as I find them transferred into my Common-place Book. There may be one or two verbal alterations, or sentences omitted, but the principal part is from the source above named. 
I have, perhaps, been guilty of digression in offering this explanation, but that is better than dishonest or disingenuous dealing, "Est enim benignum, ut arbitror, et plenum ingenui pudoris fateri per quos profeceris."

A long loop of strong string or cord $(c c)$, called the foundation, being first hung over any fixed support, one end of the twine on the needle must be tied to the loop anywhere at pleasure $(d)$. The spool is then taken in the left hand, between the thumb and two first fingers, these being laid along the back of the spool, and is to be held close up to the knot just alluded to, and under the twine. The needle, being held in the right hand between the thumb and fore-fingers, in the manner represented, is to be passed under and round the left hand, so that the twine may form a loose loop over all the fingers, except the little one. The twine must be held in this position between the left-hand thumb and the upper front of the spool. The needle is then passed back again round the spool, but allowing the twine from it to form a larger loop, to embrace the little finger also. $\mathbf{B y}$ this action the needle will be brought round in front of the spool, and then must be passed under 
the first loop, between the spool and the fingers holding it; also through the foundation loop; and lastly, over the part of the twine which proceeds backwards from the thumb to form the second loop. These steps being taken, the needle is to be held in its present position by means of the spool and the fingers, till the right hand can be brought round to pull it through the passage in which it is engaged. The needle being drawn out, and once more in the right hand, all the fingers of the left are to be disengaged from the loops of the twine, except the little one, which must still retain the second loop which was formed round it. By means of this hold of the little finger, the twine must be drawn up to the spool, and the knot formed by these manœuvres made tight on the foundation.

A succession of loops is to be made by a repetition of this process, till as many have been formed on the foundation as may be necessary to form the width of the net. In proportion as the spool is filled, or covered by these loops, it is to be pushed on to the right, and some loops allowed to drop off it at the left hand end. When the whole row is done, the spool is drawn out, and at 
this stage of the work a row of equal loops will be found hanging from the foundation-cord, and attached to it by knots, which will slide freely on it, because that cord is not involved in them.

Having thus formed one row of meshes, the work is turned over, so as to reverse the ends of that row, in order that in netting a second back again, with regard to the direction in which the first was made, the workman may still be able to proceed from left towards his right hand. To commence this second and all subsequent rows, he places the spool again close up to the bottom of the last row of loops, and repeats the action with the needle as before, only that instead of having to pass the needle through the loop of the foundation, he passes it in succession, for every new knot, through each loop of the row already done, each knot being thus formed at the bottom of the loop above it.

In fig. 2, the knot formed at each stitch of netting is shown undrawn, to explain the turns of the twine which form it. Fig. 3 represents a portion of two rows to a larger scale, by which the nature of the sliding knots and meshes of which the whole net consists, will be understood. 
It must be observed, that in using the needle, a sufficient quantity of twine must be kept always unwound off it to allow of its being moved freely round the pin and hand, and in proportion as this quantity is used up, more is to be given out by turning the needle over endwise between the fingers and thumb, and thus allowing the twine to escape from between the prongs and tongue. When all the twine is used off the needle, a new portion must be put on, its end being joined to that of the former by a bend knot.

In making nets, it is important that the meshes should be regular and equal; and though the spool determines the size, yet, unless each knot is drawn up equally tight by the little finger, there will be an irregularity in this respect, which will spoil the set of the work.

When the net is completed, the foundation is untied and drawn out; by so doing the row of knots on it of the first series of loops will open out, leaving a plain row of loops on that edge of the net; each of the other sides will also be found to have a similar edge. 
Note IV.

Dignus vindice Nodus.-HoR.

\section{The Bend Knot}

Is as valuable as his right hand to the netter. It is very simple, constantly required, and completely effectual.

First-Take two pieces of twine, represented in fig. 7 by $a . a . a$. and $b, b . b$. Bend $b . b . b$. into a loop; hold the loop between the thumb and fore-finger, of the left hand, somewhere towards $d$. Take the other string a. a. a. in your right hand, between the finger and thumb, and thread its end into the loop, as you would thread a sewing needle, holding the loop in the same position as you would the needle. Then,

Secondly-With the right hand, keeping the left still holding the loop in the same position as before, bring the end of the string $a . a$. a. downwards and towards the right. Then, 
Thirdly-Pass the end of the string $a_{0} a . a$. behind the two legs of the loop from right to left. Then,

Fourthly-Bring the end of the string $a_{0} a, a$. round, and in front of the two legs of the loop from left to right, under the string $a_{0} a_{0} a_{0}$ and over the string $b . b . b$. Pull both strings taught, taking care that the knot bites and does not slip.

The knot is represented in the figure in an horizontal position; in making the tie, the loop is held perpendicularly all the time. A bodkin with a large eye and a piece of coarse thread are excellent materials to practise with, the former representing the string $b, b . b$. and the latter the thread $a, a, a$. 


\section{Note V.}

Uno avulso non deficit alter.-VIRG.

\section{How to Repair Damages.}

M. Duhamel explains very clearly the mode of mending damaged parts, but he appears to me to refine somewhat unnecessarily on the matter, and hence renders the subject more complicated than it need be ; much of his article, however, is so well arranged, that I shall transcribe the first part of his instructions verbatim.

"Pour expliquer le plus clairement qu'il nous " sera possible comment on doit raccommoder un " filet, nous supposons que le filet, fig. 8, a un trou " au milieu de l'espace où les mailles sont mar"quées par des points. Il faut commencer, " comme disent les R'habilleurs, par couper le filet, " c'est a dire, qu' il faut augmenter le trou, non" seulement en coupant ou retranchant tout ce qui " est endommagé, mais de plus en entamant sur 
" ce qui ne l'est pas, de façon que toute la circon"férence du trou soit terminée par des angles de " mailles, à la pointe desquels on ménage le nœud "qui retient la maille du vieux filet. Tout cela " est représenté dans la figure. Les endroits qu" " on doit couper sont indiqués par de petites " lignes transversales, au dessus desquels on voit "le nœud du vieux filet, qu'il est important de " ménager. Aux endroits marqués, $a * a *$, les deux " jambes des mailles sont coupées, et on n'a coupé "qu' une jambe en deux endroits marqués, $b$. $b$. "Il faut donc concevoir que, quand on a coupé le " filet, toutes les mailles ponctuées n'existent pas ; " elles indiquent seulement les mailles qui ont eté " détruites, et qu'il faut remplacer par de neuves." M. Duhamel then goes on to describe very minutely " l'ordre qu' il faut suivre en formant " ces mailles," but inasmuch as I think, as I have already said, that he refines too much on the subject, and that his plan is more difficult to practice than the more simple one I have adopted in mending, I shall venture to describe the latter only, although in so doing I may appear somewhat presumptuous. I so fully agree with him, that " il est évident que cet endroit ne peut être bien 
"rétabli sans que les mailles qu'on formera " ressemblent le plus parfaitement qu'il sera "possible" to those which are removed, that I think his instructions to save the knots of the old net are not conducive to the desired end.

I should say, look first of all carefully to see that you have got your net before you in its proper position, as in the figure. This requires attention, because if either of the sides $\mathrm{C}$. or $\mathrm{D}$. were uppermost, the mischief would be increased when you came to cut away according to the fore-named instructions; but, having taken care to place your net before you in the order in which the rows were originally worked, begin by cutting away as shewn in fig. 8 by M. DUHAMEL; but, instead of preserving the knots a. a. a., unpick them, and shake them out; these knots are unsightly, serve to retain moisture, and thence become rotten, and are of no use; if unpicking them is a little troublesome occasionally, retaining them at least balances this inconvenience, by causing more trouble in adjusting the new loops. The lateral knots $a^{*}$. $a *$. must not be unpicked, as that would destroy the adjoining sound meshes; for the same reason, only one side of the mesh at $b . b$. fig. 8 , is cut. 
This circumstance must likewise be carefully attended to.

M. Duhamel, in his directions, says that no spool is used in mending. Although it may be done without one, and that after a little practice at this work, the meshes will be made regular and even: yet I think it infinitely less troublesome, and that the required regularity of the meshes is much more accurately observed, if a spool be used. according to the size of the meshes in the net.

Let us suppose, then, that the cutting away is done, and a proper spool looked out, and a small needle filled with twine; we proceed to make fast the end of the twine above the knot K. fig. 9. Hold the spool and needle in the usual way, and take up the loops M. O.Q. as in common netting; when at $Q$. lay aside the spool, and make the side Q. R. This is done by means of the bend knot, the angle $r$ being the loop of the knot. You are now to begin the second row, which is worked in the same way as the first, the single thread or side, at the end of each row, being managed as at $Q$. R., and leading down to the row beneath. We have supposed the workman to have begun his first row at the left hand, and to have proceeded till it was 
completed, from left to right, as in ordinary netting. In order to work back in the second row, he has only to get on the other side of his net, or to turn his work, as may be most convenient to him; and so to go on alternately changing the position of his work or of his own body.

We will next suppose that the required number of rows is completed; we must now join the last row of the inserted part, L. N. P. I., to the old net, S. T. V. Z. This is done without a spool, by making the side I. S. fast at S. with a bend knot, round the loop of the old net at $\mathrm{S}$. Then the side S. P. with a bend knot at P. round the loop of the new net, P. Then the sides, P.T., T. N., N. V., V. L., L. Z., in the same manner. Care must be taken that these sides be of the same length as the sides of the other meshes. At the beginning, K., and at the end, Z., of your work, make a good fast knot, and leave an end, e. e., to prevent its getting loose.

It is, perhaps, needless to add that the net, whilst under repair, must be hung upon some fixed support, by a string as in common netting.

In fig. 10, two rows only are cut away, therefore those loops which have only one line cut are 
both on the same side of the net, $b . b$. fig. 10 ; whereas $b . b$. in figs. 8 and 9 are on opposite sides to each other, in a diagonal direction; hence, bear in mind, that when an even number of rows is cut away, the two loops which have only one line removed, are on the same side; but that, when an uneven number of rows is cut away, the two loops which have only one line removed are diagonally opposite to each other.

The knowledge of how to mend a net is more essential to the fisherman than the ability to make one. It may answer his purpose to buy a new net; but, if he cannot mend an occasional rent, he will soon be obliged to purchase another: for two or three damaged meshes will, if neglected, become a yawning hole in a very brief space of time. Indeed the mischief spreads with even more than proverbial stitch-in-time-saves-nine rapidity, in a net; whereas the article will last at least three times as long as one wherein tears are not immediately replaced, if it be but kept in good repair and in sound working order. Nevertheles M. DUHAMEL assures us that there are many persons who can make, yet who know nothing of mending a net; and old CALcotr, of Godstowe, a very 
neat repairer of reticular damages, has often told me that " there be many a man what may be able " to make a new net, but few as knows to mend "s 'em."

By amateur netters, as well as others, this part of the art seems generally passed by unthought of and unheeded. The owners of fishing nets, on the contrary, entertain great respect for a good mender, as the saving to them is enormous.

These observations lead me to a very interesting subject, as affording one of those little indirect proofs of the authenticity of the Gospel, which it is agreeable to trace when opportunity offers, although not, perhaps, of great importance. It is mentioned incidentally, Matt. iv. 21., that our LORD, walking along the Sea of Galilee, "saw "James the son of Zebedee, and John his brother, " in a ship, with Zebedee their father, mending "their nets." From what has been said above, we see that mending is little thought of by persons in general, even by those who, one would imagine, from their having paid some attention to net making, might have had their minds more alive to its usefulness ; whilst the owner and the fisherman are fully impressed with its necessity. It would 
then, I contend, never have occurred to the inventor of a fictitious tale to mention this trivial circumstance-trivial to a person who is not engaged in fishing; but a most essential and natural occupation for one who $i s$, to be found in-had it not really happened. An artful forger might, perhaps, have said that James and John were making their nets, or casting their nets; but mending would have escaped his attention, or have been considered unworthy of notice, in so important a work. This is indeed one of those coincidences so minute, so latent, so indirect, and so evidently undesigned, that nothing could have produced it but reality and truth, influencing the mind and directing the pen of the writer throughout his narrative, from beginning to end. 


\section{Note VI.}

\section{Ordinem}

Rectum evaganti fræna licentiæ Injecit. Hor.

\section{Bridling a Net.}

A NeT is bridled at its four outer margins when it is desirable to keep the meshes of a piece of "dead netting" square, as this manœuvre prevents them being stretched either way beyond their proper tension.

Bridling is done by netting along the last row of meshes, at each side of the net, one row with the same twine, but on a spool a full quarter less in circumference than the one used in the body of the net. Thus, if the body of the net is worked on a four-inch spool, the Bridling must be worked on a spool barely three inches. The size of the spool must be very carefully attended to; for, if it be too large, the bridle would, instead of forming a straight line along the sides of the net, hang 
down loosely in loops, and would of course be of no use in preventing the over tension of the meshes either upwards, or downwards, or laterally. If, again, the spool be too small, the bridle would brace the margins too tight, and the other meshes would get puckered up, and the body of the net would bag in consequence. If, however, the net be carefully bridled with a spool in proportion to the meshes, the net will set square as it ought. The same effect is sometimes produced by fixing the meshes to a stouter string or cord which runs all round the net, by means of knots tied at each mesh; the cord in this case is to be threaded through the meshes, mesh by mesh. See fig. 11, b. b. b. 


\section{Note VII.}

Rectius hoc est.-Hor.

How to make the Meshes set at Right Angles, by a better way than the last.

IF it be required to have the meshes of the net to set in squares, with their sides accurately at right angles with each other, like a sash window frame, the following method is to be pursued. Net one loop, which makes the first row; draw the spool out and net two loops, for the second row; the additional loop being formed by taking up that one loop which formed your first row, twice; or, as it is technically termed, by netting "two in one." Your second row will thus consist of two loops; remove the spool, begin your third row, which is to consist of three loops, the additional loop being gained as before. Continue thus adding a loop at the end of each row, until you have made your half square as large as you require; the two selvages on each side of your netting forming two sides of your square. Then before you begin to form the other 
two sides of your square, net one row of plain netting, not increasing a loop at the end of it. This done, at the end of all the subsequent rows take the two last loops up with your needle at one time, instead of only one, as in common netting, your rows will thus be reduced to one mesh at last. And the net, thus finished, will, when stretched out straight, be a complete square, and all the meshes in it will sit square instead of lozenge shaped.

But, suppose you want your net to be longer than it is wide, and yet the meshes composing it to be square, as in the other. This is effected nearly in the same way as the complete square. Form half a square as before, the length of one side of which will determine the width of the oblong to be made; when this is done, narrow on one side and increase on the other, that is, at the end of every alternate row you take two loops up at once, whilst at the end of the other rows, you net two loops into one. When your oblong is of the required length, which is ascertained by measuring the long side of the netting from $a$ to $b$, fig. 12, from the corner at $a$ to the last knot at $b$; finish off, so as to make the part expressed by dotted 
lines in the fig. 12, as you did in the case of the complete square, namely, by taking up two loops at once at the end of each row.

In the oblong net, you need not make a row of plain loops before you begin finishing off, as was done in the square net.

It is necessary to bear in mind that whether you add or diminish, it must always be done at the end of the row; and it is as well to mark the side on which you are to increase in oblong netting, lest you fall into a mistake, and increase or diminish on the wrong side, or irregularly. Many nets are messed up into a confused mass, or " made pie of," as a Printer would say, by not attending to these points.

Oblong and square nets, worked as now directed, will, when first completed, appear in the shape of a lozenge, as well as all the meshes of which they are composed; but, by stretching out the sides at right angles to each other, the nets will assume their proper shape.

It makes the angles cleaner, if, in making the last single loop, the spool be withdrawn before the needle is drawn taught, and when the spoole is removed, draw the needle taught; the last loop is 
thus, as it were, absorbed instead of remaining there to spoil the appearance of the net.

The single loop, with which the net was begun, may also be untied, or have its knot loosened sufficiently to enable the workman to draw the last loop up taught, and make it vanish, as he did the loop before named. A little practice will demonstrate this clearly.

Many netters consider it a great saving, both in time and twine, to make their oblong nets with square-shaped meshes, after the manner here laid down. 


\section{Note VIII.}

Rari nantes in gurgite vasto.-VIRG.

Of Bordering a Net with Additional Meshes.

Very few sea nets are ever seen defended from injury in this manner. It consists either

1. In netting two rows of loops along the top, bottom, and sides of a net, in coarser twine, and on a somewhat larger spool than is used in the body of the work, through which a cord is threaded mesh by mesh. Or,

2. In netting one or two rows of loops along the bottom of the net only, in twine three or four times coarser than that used in the body of the work, but with a very large spool. If the bordering twine be much thicker than the other, instead of taking up on the needle each mesh of the net in succession, the workman only nets into every alternate one, leaving the intermediate meshes loose; sometimes, indeed, he passes over two 
meshes, and works only into every third. This has very much the same effect as Bridling, but it tends more to strengthen the bottom of the net, owing to the Bordering being of stouter material. When the bottom is thus bordered, the top is strengthened by a cord threaded through each mesh, which latter are made fast to the cord, as is shewn in fig. $11, b . b . b$, by means of knots.

Of Leading (fixing leads), setting on Floats, and Mounting Nets, I shall speak under the heads of Casting Nets, Trammels, Hood-Net, Trawl, \&c. 


\section{Note IX.}

Sic veris falsa remiscet.-HoR.

\section{Of False Meshes.}

There are two kinds. 1. When they hang loosely in the angle of the mesh into which they are inserted; but which, for reasons hereafter to be mentioned, are attended with inconveniences, and possess no advantages that the other kind have not. I only allude to them here so that if a "young hand" sees them in a net he may not be puzzled, and have his nascent ideas on the subject put out of geer at first starting on his inquiry.

2. When arrived at any given point wherein you wish to insert a False Mesh, instead of netting into the next loop of the row above that you are actually making, as usual, you draw the twine and needle towards your chest, pass the needle from below upwards through the same loop into which you last netted. No knot is yet made, the twine 
simply embraces the circumference of the spool; but now comes the knot:-Draw the twine on the needle taught, pass the thumb of the left hand to the right of the twine, hold the thumb down tight on the twine and spool, so that the latter may be kept embraced by the former firmly; the rest of the twine will be at liberty, and is to be flung round towards the left, so as to form a loose circle as in the ordinary process of netting; bring the needle to the right, and pass it horizontally from right to left under the two sides of the mesh you are netting into-that is, under the two legs of the quincunx or $\mathrm{V}$ into which you have passed your needle; now let go the left thumb, pull the knot taught above the knot of the mesh into which you have been working. Net on, as usual, and you will have, by the above manœuvre, an additional loop in your row.

It is almost impossible to learn from a written explanation, even though accompanied by a drawing, which, in this case, would be of no assistance to the reader; but by perusing this Note over carefully, and then going to see the loop made by some fisherman, or netter, the instructions of both will become more comprehensible. What appears 
very easy to do when done by practised hands, is not so clearly understood when the learner gets the tools into his own power, and under his own sole direction; many of these instructions therefore may, I flatter myself, be of some use in guiding the inexperienced workman to understand what he may see done, and in reminding him of what he has seen performed, by others, though they may not be sufficient of themselves alone to instruct him altogether. If the finger-post, by pointing to the right road, aids the total stranger, or serves to remind the old traveller who has forgotten the turn, which way he is to go, we must not quarrel with it because it does not carry them the whole stage to boot.

But $\mathrm{I}$ have undertaken to advocate the superior claims of False Meshes No. 2 over those of No. 1. The false mesh, No. 2, is fixed, instead of playing loosely in the lozenge into which it is set. By allowing this play, the false and true meshes wear out and fail at those parts, owing to the constant friction. Again, the False Meshes, No. 1, not having a fast knot, slip up, and thus make the surrounding lozenges uneven and irregular, as well as pulling unequally themselves, and for this 
reason again, are liable to break; and, lastly, No. 2 is much more speedily and easily made, and is more seemly when made. 


\section{Note X.}

\section{Jungere si velit.-Hor.}

\section{Of Joining.}

M. Duhamer mentions only one mode of Joining, which I shall describe first.

I. By referring to Note VI. the reader will readily perceive that the same manœuvre will, with very slight variation, serve to join up two nets together; or the two extremities of one net together, so as to form with it a cylinder or pipe, if required.

First-Apply one net on the other, supposing each to contain the same number of meshes in the rows to be united, and that the meshes are of the same size; with a spool a full quarter less in size than that with which the nets are worked, net a row along the margins to be united, taking up two meshes, that is, one mesh of each net together on the needle at once. Or, 
Secondly-If the object be to unite the first with the last row of the same net, the workman must bring the two borders together, the first row of meshes being accurately applied on the last row; the net, in fact, being folded over on itself, like a sheet of writing paper laid on the table, with the line of duplication farthest from you; then proceed to take up one mesh of each margin on the needle at once, till you have netted the whole length together, or so much of it as you may wish.

II. Another mode of joining two distinct rows is thus adopted by fishermen. Place the two nets to be joined one on the other, keeping the two margins on which you are going to work even together, knot against knot; fix your work to a peg or vice, as at P. fig. 13., letting the rest of the net hang down loosely, as two persons folding a long table-cloth would do when they double it lengthways; the peg P. representing the hand of one of the persons, and your own left hand performing the duty of the other person's hand thus engaged. The two breadths of net are now hanging parallel with each other. Make your twine fast to the end, at A., of the two breadths by a bend knot, the last mesh of each piece of netting 
at that point forming the loop of the knot, and being united by the knot to each other at that point. The workman stands any where towards B. As the work proceeds, he must step back farther from A., till the joining is finished. The margins, A. B., must be kept stretched tight by the left hand as he works; this is easily effected by passing the fore-finger through the corresponding meshes of the applied breadths at their margins, any where along A. B., and pulling towards you sufficiently to keep the margins taught, moving your finger more towards B. as the work advances.

In order to shew the manner of making the join more clearly, it has been necessary, in fig. 14, to represent the two pieces of netting extended flat, like two widths of carpet on a floor, and for the same reason the two extremities, A. A., are separated in the figure, though, in working, they must be made fast together, as before explained. We must suppose, then, the two margins tied fast at A., take your needle and pass it under the line B. (fig. 14), over C., under D., fling the twine loosely round in the direction of the arrows, pass the needle from right to left, under C. and D., and over the twine T., any where towards 'T., and pull 
the twine taught, the knot will be formed at*. Begin again, pass the needle under $\mathrm{E}$, over $\mathrm{F}$, under G. H., fling the twine round as before, pass the needle again under G. H., over the twine T., pull taught; thus another knot of union is formed at $*$ below the other $*$. Go on till the length is finished. When you fling the twine round, and until you pull the knot taught, keep the left thumb on the twine where you have threaded it through the meshes. The knots do not bite, but the series of them down the join is kept in place by the mutual support one receives from the other.

The Sea Nets, such as those for Herrings and Mackarel, which are made in rands or breadths, are joined in the manner above described lengthways. The former have three rands, are about thirty-two yards long, and fifty meshes deep. See fig. 15, a.b.c. At the end of each year, the lowest rand, $c$., which goes deepest into the sea, is cut away along the join, and a new rand is sewn on at the top of the rand $a$., which now becomes the second one; next year the rand $b$. is removed, and a new one is joined on the top of last year's new one; the rand $a$ now occupies the lowest place, and is in its turn removed the following 
year; thus the whole net is renewed every three years. This operation is termed by the fishermen giving the net a New Jacket.

III. Another mode of joining, and, when done carefully, it is the neatest, is by uniting the two nets, or the two margins of one net, in the same way as the last row of the new piece is joined to the meshes of the old net in mending (see Note V). The first-made leg or side of the inserted, or joining work, must be made longer than the others, as also the final leg or side of the suture, for they, in fact, are equivalent to two sides of a mesh. 


\section{Note XI.}

Circus erat.-VIRG.

How to Net a Round or Cylindrical Net, without having to Join.

Net any given number of loops, and when you come to the end of the row, instead of turning the net over to net a second back again, keep the spool in the last loop, and, with the needle, pick up the first loop of the row just finished, and net into it in the usual way; this will unite the two ends of the row together, and you continue taking up each loop on your right in succession, as in ordinary netting, only that you work round and round, like one going down a corkscrew staircase till he reaches the bottom. 


\section{Note XII.}

\section{Mutat quadrata rotundis.-Hor.}

How to make a Round Net, so as to form a Bag, from a SquARE piece.

Landing Nets, some Minnow Nets (not Casting Minnow Nets), and that useful, but despised, specimen of reticulation, the Cabbage Net, are all made" on this principle, as also many other kinds of river, sea, and land " engines and devices," wrought by spool and needle power.

Net a piece of dead netting, of any number of loops in the row-3, $5,7,9,11,13,15$, as you conceive the proposed size of the net may demand -but always observe an odd number; net double the number of rows save one, i.e. $5,9,13,17,21$, 25,29 , that you have netted loops; this done, draw the foundation string out and fix it in the middle of the square piece, and net round and round it. The corner loops want a little humouring at first, 
for a few rounds. The first mesh at each corner will wear a triangular shape, but this will be no dis-sight, if carefully managed. Some netters make their square too large, which does not look well, and is by no means necessary; a small square will lay the foundation for a good-sized net, and it is always in the workman's power to increase the circumference by putting in false meshes where he pleases; but he must observe regularity in this, and divide the circle into equal parts for their insertion, otherwise the net will be lop-sided and distorted. 


\section{Note XIII.}

\section{Ego Retia servo.-VIRG.}

\section{Of Preserving Nets.}

Although the Bark of Oak is generally considered the best for tanning, that of other trees have been used with great advantage; such as elm, birch, and the wild pine. Where a tan-yard is not near at hand, the following method may be adopted for tanning nets or twine:

Reduce to a coarse powder the bark of either of the above-named trees; to one part of bark add six parts of water, and boil until the liquid is reduced to one half the original quantity; draw off the decoction into a barrel, or other convenient vessel; when the liquid has cooled down sufficiently to allow the hand to be held in the decoction without inconvenience, pass the net through slowly, that its whole extent may be imbued thoroughly with the tanning principle. The net 
is then immediately placed in a cask having holes at the bottom, to allow the liquid to drain off; the cask is then closed at top, and the contents left untouched for some days - a fortnight or sowhen they may be removed; they are then to be washed in clean water, and spread to dry out of doors. When the paleness of its colour after use, indicates that the net requires to be tanned again, the same process is repeated.

Tanning is effected also by another process :Take the bark of the root of the walnut in a green and fresh state, and cut it in pieces about an inch square; put them into a tub, and to every bushel of bark add one pail of water; boil them together for a full hour. Remove the bark, and place the net at the bottom of the tub, and then throw the bark over the top. Having let the net soak for four-and-twenty hours, draw it out, wring it well, and stretch it out to dry.

By carefully attending to Tanning, Mending, Washing after use, and Drying, nets will last a long time; but, by neglect, particularly of Mending and Washing, they become speedily rotten and worn out.

The Washing of Nets is often entirely over- 
looked by game-keepers and their masters, or else done imperfectly. Mr. Daniel strongly urges the necessity of their being thoroughly cleansed from all filth, slime, mud, and other impurities, as an effectual precaution against rapid decay, which must otherwise infallibly ensue.

And here let me observe, that we have now before us another of these highly interesting coincidences, similar to that remarked in a former page of this work, under the head of "Mending." It is particularly mentioned (Luke, chap. v.) that Simon and his partners were "Washing their Nets." Thus we find two men of different nations writing two distinct books, without any reference to scriptural investigation or scriptural authority, viz, M. Duhamel and Mr. Daniel-the first insisting on the necessity of carefully mending, the other, of thoroughly washing, Fishing Nets-both saying that these operations are too much neglected and too little attended to, except by regular fishermen; and then we find it mentioned in the Gospel History, that the earliest teachers of our religion, who, the sceptic reminds us, with a sneer of incredulity, were fishermen, were engaged in Washing and Mending their nets. Is it too much to say, 
that such coincidences as these stamp the narratives of the Evangelists with an indelible mark of truth, which no forger can imitate, how ingenious and cunning soever he may be ?

It matters not how or when we examine into the pages of Holy Writ, provided only we go to the task with an humble and teachable mind; doubts will readily disappear from before us, and conviction will daily dispel the mists from our eyes; numerous little circumstances, mentioned as it were by chance, will concur, as we proceed in the search and compare them with what passes in the world around us, to prove that in the Bible verily and indeed we " have the words of eternal life." Seeing, then, that in every kingdom of Nature, in every department of Art, "we are com" passed about with so great a cloud of witnesses, " let us lay aside every weight, and the sin which " doth so easily beset us, and let us run with " patience the race that is set before us, looking " unto JESUS, the author and finisher of our "faith." 


\section{Note XIV.}

Non certis certa figuris

Est natura coloris-LucRET.

\section{Of Dying Nets.}

Nets, though they may resemble each other in shape, are however often dyed of different colours, according to the service they are intended to perform, or as the fancy of the workman may dictate.

A Russet colour is produced by tanning, which has likewise the advantage of preserving the net (vide suprà "Tanning"), or by immersing the net in a decoction of logwood.

Green is procured by chopping green wheat and boiling it in water, then soaking the net in this green tea till it has gained a sufficiently deep tinge.

Yellow is given by immersing the net in a decoction of celandine. The yellow thus produced is of a pale straw hue, resembling stubble, and is precisely what is wanted; for nets are used, when 
thus dyed, by the fowler on stubble lands; for whose service, indeed, dyes are exclusively devoted in net-making, unless we except a Horse Net occasionally; for the fisherman never colours his devices for the sake of colouring them, though he tans them in order to preserve them.

Horse Nets may be tanned or dyed by any of the above processes; or a Black colour may be given them by making a decoction of logwood, and having ready in another vessel some vinegar into which a quantity of old rusty nails have been thrown some hours previously; pour the vinegar into the decoction of logwood, and, whilst hot, steep the net into this mixture.

Purple is produced by dipping the net into a decoction of logwood whilst hot, and then washing it in the suds of the common yellow soap.

Logwood chips may easily be procured at any coachmaker's or carpenter's yard. A decoction of this vegetable substance, mixed "with a little rhatany root, and flavoured with a sufficient quantity of brandy, forms the Fine old Crusted Port Wine of many of our Inns.

Nets shrink a great deal when tanned or dyed, which it may be in some cases very important to 
bear in mind, as making all the difference between a net being legal or illegal. "KYaN's Patent" seems to answer the purpose of tanning, but unless one resides near a Tank belonging to, or licensed by, the Company, there is some difficulty in taking advantage of this admirable invention. Nets, \&c. made of twine, \&c. bleached by acids, or other chemical process, should not be submitted to the action of the Tank. The Company's charges are five shillings per cwt. for cordage, nets, \&c. 


\section{Note XV.}

Omnia suppeditat porrò Natura.-LuCRET.

The Contrivances adopted in Nets resemble those exhibited in the Works of Nature.

Whenever we turn our attention to the Works of Nature, we find not only a copious source of entertainment, but also of information, which is practically useful and applicable to the several arts of civilised life.

It may, however, appear to some perhaps, at first sight, that one is guilty of desecration in venturing to trace any resemblance between the great and glorious visible works of GOD, as displayed in the universe, and the comparatively weak and trifling exhibitions of contrivance in the art of net-making. But I think, nevertheless, much as it would grieve me to offend the scruples -nay, even the prejudices-of really good and 
pious persons, that this sentiment is destitute of foundation, and altogether mistaken.

If it be not insulting to the Divine Perfection, for human beings to imitate their Maker, as far as they can, in His Moral attributes, it cannot be an act of arrogance for man to borrow, as man has borrowed, from the Physical operations of the Deity, hints whereby to construct or improve machines, engines, tools, or instruments of all kinds, which shall be productive of beneficial results to the human race.

Again, if it be not an offence to the Divine Intelligence and Omnipotence for the engineer of our Eddystone Light House, or the maker of that delicate chain of our watch which surrounds the barrel, to adopt the forms and arrangements observable in vegetable physiology or animal mechanism, I do not see how, with any show of justice, reticular skill can be ordered to keep aloof by the patrons and disciples of other, though, if you will, higher walks of art and science, whenever it may seem good for any one of them to exclaim "stand by thyself, come not near to me; for I "am holier than thou."

In venturing the foregoing remarks on this 
question, I beg at once to disclaim all participation in that charlatanerie which is somewhat the fashion now, of raising an imaginary difficulty merely for the sake of overcoming it; I have not been guilty of the childish occupation which consists in building up a pagoda of cards in order to have the pleasure of upsetting the flimsy fabric; in truth, such objections as I have stated would never have occurred to me as likely to be urged, had I not sound reasons for knowing that similar opinions, though not put, perhaps, in the very words which I have used, have been expressed or hinted at by respectable people who have not cared to give the subject due consideration.

Sir Thomas Brown, in his Treatise on Cyrus's Network Garden, or the Quincuncial Lozenge considered Mystically, Naturally, \&c., traces the existence of decussation through nearly every substance in Nature and every branch of Art. There is much truth in his somewhat fanciful speculations and theories respecting the prevalence of this net-work pattern in most objects that surround us. It is impossible not to be struck with the resemblance in the Ammonites to the ornamental forms produced by taking up more 
than one mesh on the needle at once, or netting more than once into the same mesh, or changing the size of the spool. (See BuckLand's Bridgewater Treatise, pl. 37.) A reticular pattern is also clearly delineated in the trunk of the Cycadites Megalophyllus and the C. Microphyllus. (See pl. 60 and 61 of the same work.)

In Art, our newest patterns of paper-hangings are made to resemble net-work. A lady's bag, most rudely and ungallantly, as well as untruly and undeservedly, called, a ridicule, is in truth a reticule, from reticulum, a little net. Some ladies now make their bags in very beautiful colours and devices, of silk, \&c. Patent net, much used by ladies as an article of dress, has, as its name indicates, net-work for its basis, (to use a chemical term) although indeed the form of the meshes are hexagonal, instead of being shaped like the "Quincuncial Lozenge."

But, besides these instances, which are perhaps, after all, little else than a continuation of Sir Thomas Brown's theory, carried down to things which invite attention in our own day, I conceive that the variegated scene of creation offers one or two examples of similar contrivances to answer 
similar ends existing in nature and copied by the net-maker in his art.

In the tuck of the Casting Net, which, when the engine is drawn together by the force of the leads, is puckered up into plicæ, or folds, forming a series of imperfect valves whereby the exertions of the fish to leap out of the pockets are rendered very arduous, if not entirely abortive, we at once perceive traces of that provision of nature which renders the regurgitation of the food from the stomach of the horse extremely difficult; as the rugose folds of the cuticular lining of the œsophagus, though they do not, for very wise and merciful reasons, form a perfect valve, or render the horse positively incapable of vomiting, yet prove a great impediment to the reversion of food, so, in the case of the tuck of the net, the folds do not exhibit a complete apparatus for the total prevention of the escape of the fish, yet they render such an act very rare. There are some instances of the horse vomiting, and there are many instances of the fish escaping, which, at the same time that the analogy is thereby made more close, shew how inferior the works of man are to the all-wise provisions of nature. 
In the Trammel Net, the self-acting pockets resemble the fundus, or blind pouch, which exists in the stomach of non-ruminating herbivorous quadrupeds, whereby the food is arrested in its passage onwards.

When one reads of the Mackerel Net intercepting the shoals of fish and detaining them in its meshes, he is immediately reminded of those numerous rows of horny fibres or wiery threads which hang down from the palate of the whale, thus furnishing the mouth of that animal with a plentiful supply of strong netting, in which the mollusca-his chief food-are effectually entangled.

The naturalist will recognise, in the contrivance of the Trawl Net, and the Bow or Hoop Nets, with their pockets and valves, some considerable correspondence with the valves of the heart, arteries, and veins, placed in many animal bodies by the great Artificer of the Universe, who "doeth all things well," to prevent the retrogade movement of their contents.

Is there again no similarity between the elastic mucous net-work (rete mucosum) which covers the muscles of man and other animals, and that external apparatus of the aëronaut's balloon, which, 
whilst it fits closely to the body it envelopes, can be taken hold of and raised from the parts beneath, and, when let go, resume its adherence to, and follow the shape of, the surface over which it is spread, just as the skin does in regard to the subjacent muscles?

In wire-work netting we trace, in the succession of meshes, the precise form and arrangement of the hexagonal cells of a bee's nest.

As to the wire-work netting itself, it is not very often used, though it should not be altogether discarded as a merely ornamental manœuvre. For garden-borders, aviaries, and the like, when well stretched and painted, this kind of fence combines lightness, durability, elegance, and strength. Some care is requisite in stretching it, or mounting it, so as not to disturb the regularity and general contour of the hexagons; and unless it be soon painted, the wind and weather will quickly displace the meshes. The paint not only defends the twine from the decaying ravages of moisture, but serves also to fix the knots, and prevents by its adhesiveness the untwisting of the work, as well as the over-tension or too great relaxation of the meshes at every change in the state of the atmosphere. 
Wire-work is easily performed; make a loop as usual, only just before you draw the twine taught, and previously to letting go any of the fingers, pass the needle from right to left, under that string which lies across the fore-finger; this done, complete the knot as in ordinary cases.

Before concluding this Note, I must repeat that it is highly interesting, as I conceive, and in no way insulting to the Majesty of the All-wise Creator, to occupy ourselves "when we go out and when we come in" in tracing an agreement or coincidence between the works of "Nature's God" and the contrivances of man in any one, or in the many departments of art.

I am not so vain as to expect that this my humble opinion-the expression of which, I trust, cannot do any harm to the cause of religion-will meet with universal approbation to the fullest extent, though perhaps it may, in many instances, be secretly approved when not openly avowed. Net-making is not a fashionable occupation, and therefore prejudices and fears as to what this person or that may say, and such other little impediments and trifles are to be overcome.

It is, I know, no easy task to persuade where 
habit or a false idea of dignity warps the judgment, and makes many an honest and good man believe that the perusal of the book of nature, or the knowledge of any mechanical art, unless as a means of subsistence, is, under all circumstances, frivolous, and that, as far as it can have any effect on our religious feelings, highly dangerous.

"Great and marvellous are thy works, LORD GOD ALMIGHTY," are the words of inspiration; and in the building of Solomon's temple we find that carved representations of " nets of checker work," and " pomegranates," and " lily work," all copied from Nature or Art by the builder-were used indiscriminately as ornamental designs for that glorious edifice, especially dedicated to the honour of GOD. What need is there for farther evidence that the book of Nature is in fact the hand-maid to the book of Eternal Life? 


\section{Note XVI.}

\section{Peragrans}

Invenies intus multarum semina rerum

Corpore celare, et varias cohibere figuras.

LUCRET.

\section{Of Different Kinds of Nets.}

IT is by no means my object, in these Notes, to enter into a minute description of all the Nets used for various purposes; at the same time, my aim has been to analyse the structure of a few of the most common in a more journeyman-like manner than that in which M. Duhames has noticed the numerous nets in use in France, and has generally described in his Traitè des Pêches ;" though he is the only writer that I know of who has said so much about, and entered so far into the details of, netting. The following account of nets is intended rather to furnish examples of the foregoing rules, than as a complete catalogue of every net, and of every mesh and loop in every net; yet I hope that, as a whole, this little volume 
may enter into particulars sufficiently to make a beginner feel so far at home with his spool and needle, as that he may be capable of seeing, by a little examination, how any net he shall chance to meet with is made. Without some such knowledge as this, one net appears as good as another for any purpose to the unpractised, and all nets a jumble of twine without order, or plan, or object. Nearly all other nets will be found to be modifications of those herein described. The Cleeching Net is made on the same principles as the Landing Net; the Trawl and the Trim-tram vary in size, but not in general formation; other Nets, in some instances, combine the principles of more than one net; to the Wings of the Drag occasionally is given a Body or Bag, like that of the Hoop Net and its Funnel. A net-maker, indeed, is a privileged person, and may indulge in more fancies than even the poet or painter is licensed to attempt, without the spectator being ever once inclined to laugh when he enters his workshop. The tail of one species is affixed to the wing of another sort, with perfect impunity, and one net is often compounded of " undique collatis membris," and the ingenuity which it evinces is praised rather than the heterogeneous 
qualities which it combines censured. It has always, in truth, been to me a great source of amusement to hunt out various specimens of nets, and then to trace the mode in which they are manufactured. To furnish the means of so doing to others, and not to destroy the interest which accompanies any pursuit so long as something yet remains to be done, more than has been done, has induced me to send these sheets to the press.

I never could comprehend the amusement or pleasure which, as it is said, a certain French nobleman found, in having a great many birds driven into a corner, and then shooting at them from the window of his coach, as fast as his guns could be loaded for him by an attendant. I truly pity that man too, who, when business, or not knowing what else to do, invites him out of doors, can ride or walk his distance doggedly without deriving the smallest amusement, or taking the slightest interest in any one object that surrounds him; who goes pounding and plodding on his way, without any curiosity, without any incitement, to induce him to deviate from the beaten path or dusty road; seeing every thing, but looking at nothing. 
I have experienced great pleasure and interest in considering and observing the merits of the "Quincuncial Lozenge," in all its varied forms and figures, and even when deformed and disfigured; for, to a netter, a grievous rent affords an opportunity for the exercise of his ingenuity and skill, and he looks upon his work with no small complacency, when, in the course of ninety or one hundred feet "unus et alter assuitur pannus qui laté splendeat" in bran new twine.

I have been, for some time, occupied in forming a little museum, of a novel character at all events, whatever other good or bad qualities it may possess; but of which many distinguished naturalists have done me the honour of expressing some approbation; it consists of models of various nets used in our sea and river fisheries, also of those devoted to other purposes, such as fowling, horse, game, and other nets for general use. They are made on a scale of an inch to a foot, in Taylor's Persian thread. It is seldom that I have not something in hand in the netting way, which I work at "subscissivis temporibus," or in a winter's evening. It is surprising the progress one makes, if he will only keep his net ready to work at when- 
ever a spare minute or two offers; which time would otherwise be spent, (may I say wasted ?) in doing nothing, or in "wondering why" this, that, or the other does, or does not, happen; and if five or six loops be only added, it is "autant de gagné" - semper ad eventum festinat." I feel convinced that if men, when boys, were taught to net-as it was my good fortune to be in my younger days-or to perform some other manual art, we should never feel the alleged deficiency in the English language of a word to express "ennui;" nor would so many of my fellow-men yield to sleep before the fire in an evening, and thereby run the risk of "falling into that same," as poor Sir William Pepys confesses in his Diary that he did, to the injury of his person. I wish I could hope that this little treatise might save but one man from this inconvenience, and then indeed I should rejoice that I have pressed my Notes into so good a service. Of course every body thinks his own pursuit the most delightful and useful of all, upon the same principle, though somewhat inverted perhaps, that, as PLINy says, "suus cuique morbus videtur atrocissimus ;" so no wonder if I "6 magnifie decussation." 
No. 1-The Casting Net is worked round and round (see Note XI.), and the number of the meshes vary, as well as their size, according to whether it is intended for Gudgeons, \&c. or Minnows; in either case, it would be a great loss of time and expense if the whole net were made on one spool so small as it is necessary the lower part of the net should be; spools, therefore, of different circumferences are used, diminishing by degrees from the largest to the smallest, from the top to the tuck. A casting net, made on the following plan, will give about sixteen yards in circumference round the tuck:-Net thirty-six loops round with double twine on a spool two inches and a half in circumference. Net four rounds. Then use single twine on the needle; put in at every third loop a false mesh (see Note IX.). Then net two entire rows of " $\mathrm{dead}$ netting," but, on going round the third time, you set in a false mesh immediately under each of the previous false meshes; and so you proceed downwards. When you have netted two feet down on the two-and-a-half inch spool, take another, one-eighth of an inch less in circumference, and net one foot down; then change again, and take 
a spool one-eighth of an inch smaller, and so continue netting a foot down on five other several spools, each spool diminishing in circumference by one-eighth. At the commencement of the eighth foot, set in six false meshes between each of the original quarterings, the net will then consist of about 540 meshes round, in all probability; but if not, and you find that it will be nearer that number if you go on widening either along the old lines of quarterings or along the new ones, or both, for another round; do so; but take notice, the last four rounds on your eighth spool must be netted in double twine. This done, take a ninth spool, one-eighth less than the last, and net about two feet six inches of dead net for a tuck, the last two rounds to be netted with double twine.

The circumference of the spools and number of rows netted on each, must be increased or diminished, according to the fancy of the workman; and this again, will, of course, depend on the use to which he means to put his net.

For a Minnow Net, a two-inch spool may be considered a good size to begin the first two rows upon; then net ten inches below that on a spool one inch and seven-tenths circumference. Then 
run down five inches on a spool one inch five-tenths. Then five inches more on a spool one inch threetenths, and so on five inches more each time you change, on four several spools, each diminishing one-tenth of an inch in circumference. Net two feet of dead netting for a tuck, eight-tenths circumference. The false meshes to be set in as in the larger net, and the rows of the double twine to be netted in the same places as before described. Different netters may follow different plans, as to minutiæ, but the general principle is the same in all.

As far as netting goes, the Casting Net is now finished-but it is not complete. It must next be leaded. For this purpose, a thick line, either composed of horse-hair, or of a fasces of threads consisting of five or six lengths of stout twine, is to be threaded through leaden beads of an eggshape, about an inch and a quarter long, and rather more than an inch circumference at the thickest part; about two inches of line may be left between each bead, and the whole necklace (if I may be allowed to call this rough article by so fair a name) is to measure in length about one foot less than the circumference of the net at the border of the 
tuck. The necklace is sewn along the last row of the tuck, mesh by mesh, with stout twine; when you come to a bead, make a tie, and simply pass the twine through as many meshes as the length of the lead occupies; then make another tie at the other end of the lead, round the line; and proceed to sew as before, until you come to a second lead, which is to be managed as the last; viz. by tying the mesh of the tuck, on each side of the lead, fast to the line; and simply threading the sewing-twine through the four or five meshes that extend along the lead.

Fig. 16 represents the form of a Casting Net, the lines $a$. $a$. a. shew the direction of the false meshes running down the net and increasing its circumference. Fig. 17 shows a portion of the necklace sewn on to the last row of the tuck, $l$. $l$. being the leaded line; L. the leaden bead; $t$. $t$. the tie which fixes the mesh on each side of $\mathbf{L}$. to the line; s.s.s.s.s. the twine threaded simply through the meshes which extend along the length of the bead.

The necklace being sewn on all round the circumference of the net, we must now turn it up inwards to form the Pockets. This is done by 
means of bits of stout twine, about three inches long, $d . d . d$. fig. 16, and double, being tied fast at one end to the leaded line, and, at the other, to one of the meshes at that part of the net which was netted in double twine before the tuck was begun. The tuck is thus looped up at about every foot all round. In fig. 16, b.c. b.c. is the tuck doubled up, and forming pockets inside, into which the fish fall.

Mr. Ayton, of St. Andrews, Norwich, has invented a very superior kind of Casting Net, for catching large fish, which otherwise often escape, owing to the tuck being too small; it does not do, on the other hand, to make the tuck very large, for it impedes the sinking of the net most materially, and renders it too slow in its operations. I once worked a Casting Net with a tuck of sufficient calibre to admit large fish, for a friend of mine; but it made the net too buoyant, and therefore did not answer the purpose. Mr. Ayton's improvement consists in having no tuck; or, rather, in having a large self-acting one, of an immense size and very effective; and all this without impeding the sinking in the slightest degree. Mr. Ayton, in the most obliging manner, 
sent me a description and drawing of his invention; but, as I conceive it to be a strictly confidential communication, I shall not transfer his letter or illustration to these pages. The price of one of these improved nets is, I believe, $£ 1.10 s$. Mr. Ayton has likewise invented a very ingenious Fowling Net, on so comprehensive a plan that its application may be extended to game of all kinds, yet it is by no means convenient for the poacher. The price of this is $£ 2.2 s$.

I have entered somewhat minutely into the structure of the Casting Net, but that was my object; yet, to make the matter as little intricate as possible, I will here give in brief the recipe for the mere netting of a Casting Net of sixteen yards circumference.

Net thirty-six loops round on a two-and-a-half inch spool-double twine for four rounds. Set in twelve false meshes. Two rows of dead net, and set in false meshes again in the same line with the others, and go on thus setting in false meshes till the net is about 540 meshes in circumference. Net two feet down on the first spool, then one foot down on each of seven other spools, each spool diminishing in its circumference one-eighth 
of an inch. Six false meshes to be set in between each of the original quarterings at the commencement of the eighth foot. The last four rounds on the eighth spool to be netted in double twine. Then net two feet six inches of dead net for the tuck, last two rounds with double twine. To this I shall add a short recapitulation of the mode of mounting the Casting Net when netted. Egg-shaped beads of lead are to be threaded on a line, and this necklace is sewn with running stitches along the lowest row of the net, mesh by mesh; the interval between each leaden bead being about two inches; the necklace is then turned upwards and inwards, and fixed to the double-twine work above the commencement of the tuck, at about every foot, by means of a double string three inches long, more or less.

Some foreign Casting Nets are made without any tuck at all. The net in these is terminated by the leaded line sewn along the last row. The first row at the top of the net, too, is managed differently from that in the ordinary Casting Net. In the latter, a line is threaded through the loops at that part, and then is fastened to itself a few inches higher up; but, in the Casting Net we are 
now considering, the top row of loops is tightly bound round a ring ahout an inch and a half broad, and channelled all round in its outer circumference, so as to prevent the net being displaced when cast; the ring is about half an inch thick, and two inches diameter in the clear, or inside measure, and is made of horn or brass. Along the leaded rope at the bottom, are to be fastened at one of their extremities, several strings or lines, at the distance of about one foot apart. These lines are to pass up the whole length of the net inside, and to be tied together at their other extremities to the main rope or rean, which passes through the ring above described. If we suppose the net extended, after being cast in the water, to the utmost of its circumference, it is evident that by pulling the main rean, all the vertical lines or reans which are fixed to it, will follow; and will have a tendency to meet, or impinge, at the point of the cone of the net; and they will thus draw together the leaded margin of the net below, and will pull it upwards in puckers or pockets, just as window curtains, or green curtains at theatres, used to be, and in some instances still are, drawn upwards from the ground towards the ceiling in folds or corrugations. 
All the fish which happen to be under the net will hence be caught, unless it be a very few whose size permit them to escape through the meshes.

This net has certainly less work in it for the netter, and has no tuck to impede its sinking for the caster; yet it does not appear to be very effective, by all accounts. It is very rarely used abroad, and I have never met with one of the kind in England.

No. 2.-The Trammel, or Flue, consists of three separate parts, the two wallings and the lint. The latter is suspended loosely between the two former like a curtain, it being made twice their length and twice their depth. The length and depth of the net will of course depend on the nature of the water whereon it is to be used. The lint is to be netted either in lozenge-shaped meshes or in squares (see Oblong Netting, Note VII.), on a two-and-a-half inch spool. One walling is to be made of the same length and depth as the other, but only half the length and depth of the lint. The wallings are netted in squares or in lozenges, on a spool of about twelve inches circumference, so that the whole mesh of the walling is nearly six inches square. Thus if the lint be ninety feet 
long and ten feet deep, each walling will be fortyfive feet long and five feet deep; and whilst the meshes of the lint will be about one inch and a quarter square, those of the walling will be four times that size, at least.

Having netted the three parts-the lint in good three-twisted twine, as fine as may be consistent with strength, and the wallings in much stouter twine, three twisted-we proceed to mount the net. Fix each of the four corners of one walling to four pegs driven into the ground, which should be as free from rubbish or high weeds, and other obstacles, as possible. The walling must be stretched as tight as you are able. Then pass through each mesh all round the lint a stout line of twine, as thick as that with which the walling is netted; this line and likewise the lint, is made fast at the corners to the four pegs; the former is drawn tight, but the lint, from its being longer and wider, sets loose ; the meshes must be distributed along the line with as great a regard to regularity and equality as you are able. Over the lint is next applied the other walling, the four corners of which are to be made fast to the four pegs. Thus the three pieces of net are now applied one over 
the other, having the lint between the two wallings. Have a stout cord threaded with round corks about two inches diameter and half an inch thick, fix this cord along the top of the net by means or bits of twine whipped two or three times round, and embracing the line of the lint, the cord, and the margins of each walling, and tied, at those points where the cord meets the angles of the walling's meshes, into a fast knot. The floats must be so distributed along the cord as that a float shall come at about every six inches. The cord is made fast down each side of the net in the same manner, being fixed by a knot or tie at the angle of each mesh of the walling; but the cord has neither float nor lead on it. The bottom of the net is leaded with small plates of that metal firmly embracing the cord and beaten to it with a hammer, as the tag is fastened to the boot-lace. The cord is fastened to the bottom of the net, as the cord along the top and sides is. Some use bullets, or beads of lead, as in the Casting Net, and attach them to the cord by a length of twine running through the last row of the lint, and tied at every bead, as in the line of the Casting Net; in either case a lead is fastened at about every four 
inches; but this, and the number of floats, and length and depth of net, must depend upon circumstances. The cord must be bent into a loop at each end of the top of the net, for to these is to be attached a rope when the net is used. The meshes of the wallings must always be made large in order to allow ample space for the fish to enter and strike against the lint, which being suspended loosely, yields to the fish, and protrudes through the meshes of the walling on the other side, thus forming a bag into which the fish falls, and cannot extricate himself.

Some netters tie the three layers of net together at each mesh of the walling throughout its area where they cross at right angles, with a view of strengthening the net and preventing the lint getting all huddled together at the bottom when suspended in the water. Floats and leads should always be bored only just large enough for the cord to pass through them. Some netters use flat pieces of cork cut thin and the corners somewhat rounded; and instead of one cord, they have two smaller ones running parallel, between which they place the cork, and whip the cords together at each end of the float, thus keeping it in place. 
No. 3. - The Hood Net is made in the form of a bag, and is netted from a square (see Note XII.) on a two-and-a-half inch spool. The bag is seven feet deep. The two top rows must be of double twine. At about sixteen rows from the top a float is made fast in any part of the purse or body of the net, and another parallel to it about one foot apart; and two more about a foot and a half lower down towards the bottom of the bag, in the same line as the other two floats. The mouth of this net is sewn on to an iron hoop two feet four inches diameter, and thus far it resembles a Landing Net; but it is always used with the mouth downwards, whilst the corks keep the bag floating in a position half perpendicular and half horizontal on the water.

The mouth is held downwards by means of a long pole fastened into a socket, which socket rises perpendicularly from the centre of an iron arch, or half-hoop, measuring two feet four inches across at its widest part; this semicircle is fixed, at each end, to and across the iron hoop. The fisherman, by this contrivance, puts the Hood Net down upon a fish, in the same manner that one places an extinguisher over the flame of a lamp 
or candle. It requires some practice to manage the Hood Net adroitly.

No. 4. - The Hoop Net consists of two parts. The body and the valve or funnel, which are united in the manner hereafter to be described. Begin with the body at its lower, or pointed end, and work up to its mouth thus:- net thirty-seven loops round on a four-inch spool, one row. Take a two-inch spool, and net twenty rows of dead net. In the next row, set in five false meshes equidistantly. Then twenty rows of dead net, then a row with five false meshes. Then twenty rows of dead net, then five false meshes in the next row. Then thirty-six rows of dead net; net the thirty-seventh row in double twine. This done, cut off both threads, leaving ends, and fill a needle with single twine; but the last row you have netted being in double string, you have an upper and a lower row; to the end proceeding from this lower row, where the double thread was cut off, and from which the valve is to issue, tie the twine you have on the needle, and work as follows, taking care to pick up only the loops of the lower row on the needle as you go round:-Net fourteen rows of dead net, then, at equal distances in the circumference, 
make, in the fifteenth row, eight stole meshes; i.e. take two loops up at once eight times in that row. Then net two rows of dead net; in the next row eight stole meshes, and so on, as before, for three times more; after you have, for the fifth time, put in eight stole meshes, net a row of plain netting; then lay aside your two-inch spool and take a twelve-inch, on which net one row. The funnel, or valve, is now finished, and must be reflected inwards to gain its right position. You now take your needle, charged with single twine, and join on to that other row which was left before, and where the funnel issued from the body of the net. Net eleven rows of dead netting on your two-inch spool. In the next row, set in five false meshes, at equal distances from each other, and continue to set in five false meshes at every fourth row for seven times, leaving three rows of dead netting between. After you have set in your false meshes for the seventh time, make seven rows of dead netting. Then one row on a four-inch spool. This last row is strung on to a length of wood about six inches long, and bent into a bow (B.B.B. fig. 19); a piece of stout string keeps the two extremities bent, answering to the string of an 
archer's bow, and the last meshes of the net's mouth are strung on to this string as well as on to the bow. The bow and its string acting upon the meshes in the same manner that the rod of a curtain gives support to the rings. A moderate weight is generally attached to the bow at its extremities, somewhere towards B.B. Four hoops $H . H . H . H$. are placed round the net through the meshes of (reckoning from the pointed end) twenty-first, forty-second, sixty-third, and one hundredth row. The hoops are made larger as they proceed from the point towards the mouth, and all are made of much slighter wood than the bow. The diameter of the first, or smallest, hoop is about one foot five inches; the next about one foot seven inches; the third about one foot ten inches; and the fourth about two feet. The hoops are bound to the meshes by twine, after they have been passed through; and this of course is done before the ends of the hoop are lashed together.

In some Hoop Nets more than one funnel is inserted, but many fishermen prefer only one. The large loops of the funnel at its point are knotted together in bundles of fours to four separate reans, four feet four inches, or so, in length. 
These four reans are tied together, and passed through a mesh in the first or second row of the body of the net towards its point, from within outwards, and are united to the main rean $R$., which main rean is strung through the last thirtyseven meshes of the body of the net at $R$. In the figure 19, the funnel or valve is marked $V$., the other part represents the body of the net. The principle of this net is analogous to that of the mouse-trap.

No. 5.-Minnow Nets, I have made with very small meshes on a spool about six-eighths of an inch circumference. It is begun on a square and then netted round, and several quarterings or false meshes set in all round repeatedly. It is made very shallow, only bagging enough to render it loose or dished, when the outer row of loops is sewn on to the iron circle made to receive it. The hoop is about twenty-three inches in diameter. Three strings, about four feet long, are attached to the hoop, like the chains or strings at the circumference of the dish of a scale, and tied together at their ends. The net is let down and pulled up by means of these strings, which are held in the fisherman's hand. There is a great deal of work 
in this trifling net, the meshes being very small. The last row is to be netted in double twine.

No. 6. -The Trawl Net is a very large net, and and is composed of two separate pieces, called the upper and lower blade or leaf. The meshes are about two inches square. The under blade is made of rather coarser twine than the upper. For the under blade, net 160 loops in double twine, two rows; then a row with single twine; in the next row set in a stole mesh at the beginning of the row, that is to say, about four or five meshes from the margin; and set in another stole mesh towards the end of the row, at the same distance from the termination as the other was from the beginning of the row; net three rows of dead netting, then set in stole meshes again as before; do this once more, leaving three rows of dead netting, as before. Afterwards, go on setting in stole meshes less frequently, i.e. leave five complete rows between, until the width of the blade is reduced to thirty-six meshes, then net about four or five feet in double twine, for the hose or tail.

The wings are now to be set on; for this purpose you must begin working at the other extremity, or 
top of the blade. Tie the twine on at whichever end you please, of the row on which you are going to net; net on fifty-six loops; stop; net back; at the end of the third row set in a false mesh quite at the extremity, but when you net back again do not take up this false mesh, but let it hang; so at the end of every alternate row make a false mesh, but do not take it up; at the commencement, however, of every row which alternates with those to which you append a false mesh, and at about three or four meshes from the beginning, set in a stole mesh; thus the false meshes will always be on one side, and the stole meshes on the other side of the wing; reduce the wing to about eighteen meshes, then net two rows in double twine without adding or diminishing. Thus one wing is done. Make the other in the same way, and take care that the one is exactly the same as the other. The netter must herein observe the same precision which the coach-maker does in making one wheel of the same circumference as its corresponding wheel. The under blade being now finished, we pass on to the suructure of the upper blade. Net 180 loops in double twine, two rows. Then, with single twine, net forty rows of dead net; then 
diminish from 180 to 160 by stole meshes as before, taking notice that this reduction must be made before you come to a level with the double rows whence the wings rise in the under blade. Diminish from 160 to 36, as you did in the other blade, putting in precisely the same number of stole meshes as you did when working down that other blade; when you have reduced to thirty-six meshes, net the same length of hose, with double twine, as before.

The blades are now finished and require to be sewn together down their sides or margins, which is to be effected according to the directions given in Note X. sec. 2. The next thing is to bind the sides or seams where this suture has been made which unites the one blade to the other, with a stout rope to strengthen the fabric down the sides; this is done by whipping it round with twine, and making ties occasionally to keep the rope fast to the margins. The back has a rope simply passed through the upper meshes where they are double, which rope is extended round, and is sewn to the bosom, being tied to the false meshes of the wings by knots. This being done the two blades are, in places, sewn together in lines to form pockets, 
about four on each side, see fig. 20 , dotted lines A. A. A.A.A.A. B.B.B. represents the bosom. $W . W$. the wings. At $L . L$. loops of rope are fixed for hauling the net into the boat. The two leaves or blades must be exactly of the same length, for when joined, the top row of the wings of the under blade must be on the same level as the top row of the back of the net, or upper blade, and the hose must end no less accurately at the bottom. When the trawl is in the sea, a long beam of about thirty feet in length, and seven or eight inches in circumference, is lashed to the upper margin of the net extending from the point of one wing, along the back, to the point of the other wing, see fig. 22 . This beam is fixed at each end into irons made in the shape represented at $I$. in the fig., which serve to keep it on the ground and facilitate the drawing of the net. A heavy rope, generally made of old netting tightly twisted together and bound round with stout twine, is lashed along the bosom of the net; thus equipped the trawl is put into the sea attached to a mast by a rope communicating with each end of the beam by a bridle, b. b. fig. 22 . The bosom touches the ground, and the upper blade and beam are uppermost. The heavy rope 
of the bosom disturbs the fish; they are however stopped from escaping by striking against the upper blade, which extends beyond the bosom; so they swim down the trawl towards the end of the hose; but this is tied up like the mouth of a bag; they next attempt to return towards the the bosom; but are entangled in the pockets into which they fall, and which only open inwards towards the tail or hose.

No. 7.-Shrimp Nets. One kind is called a "Trim-tram," and is, in fact, only a trawl in minature, being perhaps one-tenth, or less, in size, and without pockets. Another sort is such as are used at Brighton, Hastings, \&c. They are made as follows:-Net on a four-inch spool 160 loops; net on this a second row; net four rows on a three-inch spool; net six rows on a two-inch spool; then take a nine-tenths spool and net 160 rows. This will produce a piece of netting as in fig. 23. At the lower part, cut away, in the direction of the transverse line, a.b., the corners $a . b . c$, which produces a jagged margin at $a . b$. ; fold up the corners $a . a$., and join $a . a$. to the corners $b . b$, sew up the two lateral and jagged margins thus brought together; by this manœuvre the net bags 
in that part. The net is mounted on a wooden and string frame. The upper row of meshes, $A . B$. fig. 23., is threaded with a length of stout twine, measuring five feet, more or less ; this twine thus threaded is strung tight along, being fixed at each end of, a spar, or piece of board about three inches wide, and half an inch thick, S.P. fig. 24 . bevelled off at the edges. Parallel to this spar, and at about three feet from it, is a round wooden beam, $B . B$., or stick, two inches in diameter, round which the opposite margin of the net is sewn. Two strong strings, T.T., to which the meshes of the shorter sides of the net are sewn, form the other two sides of the frame. These two cross bars of wood, and the two pieces of twine which connect the bars at their ends, are kept at right angles to each other by a long pole, C. C., which has one end fitting into a mortice in the middle of the spar; and is farther attached, or hitched, at any point so far down its length as shall serve to keep the side-strings stretched, to the centre of, and at right angles with, the small wooden beam before named, by any device that it may suit the fisherman to adopt: a kind of wooden cleet, for instance, so as that he may shift his pole and roll up his 
net conveniently for being stowed away. Fig. 24 represents the frame; S. $P$. the board; $B . B$. the beam; $C$. the pole; T.T. the side strings, which are kept stretched by $C$., the pole, being fitted into the mortice at $A$. of the board and fastened at the point $P$. of the pole. The shrimper pushes the net before him by means of the pole. In some nets the board is pierced with holes along its length, to which the upper row of meshes are sewn, instead of being strung as above described.

There is yet another form of Shrimp Net, which is more picturesque and rustic, if I may so say, than any. See fig. 25. The net is smaller than that in the previous figure, and is made somewhat differently in another respect, besides having fewer meshes. The corners are not cut off, but the side of the square from $c$. to $c$. (see fig. 23) is folded together, the two corners, $c$. and $c$, being fastened to each other, and the perpendicular margins sewn down their whole length, from $C$. to $D$., fig. 25 .

No. 8.-The Stake Net is of very simple construction, being so many lengths or pieces of dead netting, fixed by stakes into the ground, in the following manner ; the leader, or wing, which narrows 
towards the end, as hereafter stated, is diminished in width by the usual process. Fig. 26 shews the shape in which the net is placed, and is, as it were, a ground plan of the building. The mesh is about two-and-a-half inches square ; the distance between high and low water mark on the shore is the site occupied. One extremity of the net is reduced in depth, and the end of this one wing is fixed and supported by stakes (as the rest of the net is supported), and placed on the shore at high water mark; the other wing, at low water mark. The concavity of the sweep of the net between its two ends, called the court or chamber being opposed or open to the flood tide running up the river, the Salmon, which in their passage up along shore strike against any part of the net, are conducted by its form to the chambers, from whence they can find no retreat. Many fish, in the wide part of the estuaries, ascending with each flood tide, and returning with the ebb, it is not unusual to have Stake nets placed in the reverse position, with the courts or chambers open to the ebb tide, on purpose to meet this disposition of the Salmon; and they do actually sometimes catch as many fish in their downward as in their upward course. The 
spawned, or unclean fish, are not caught in the Stake Nets, nor are the fry, owing to their keeping the middle of the stream, in consequence of their being in a comparatively weak state, while the clean fish, which is in the best condition for food, and in a state of vigour and health, roams at large throughout the shallow and deep water.

No. 9.-The Cinque Port Net is a sort of square net, resembling a cage, and having five entrances into it, whence it derives its name. It is a very serviceable net in any pond or river, and is equally good in swift or standing water. In order to make this net, there must be provided four large and straight poles, answerable in length to the depth of the water. The ends of these must be sharpened in the manner of stakes, and there must be notches, within a foot of the sharp part, to fasten the net to; and, at convenient distances on the poles, there must be another set of notches, for the fastening the other end of the net. The bottom of this net is four-square, without any entrance. A boat must be taken out with this net, to place it properly. The four poles must be fixed in the bottom of the water, in such a manner that each may answer to the other in a directline, and they 
must stand at such distances that the net may be drawn out as stiff as possible between them. If the net is to be fixed in a standing water, this method alone will do very well, but if it be a smooth stream, something more is necessary, otherwise, the motion of the water will keep the net playing about, and this will frighten away the fish. To prevent this, four strong sticks are in this case to be fastened along the tops of the others, so as to make a sort of frame to straighten and strengthen the others, and keep all tight. When the net is perfectly fixed, it represents a cage, and the sides, top, and bottom, are kept so firm, that the fish do not regard them, but seem to take them for weeds; but going in at the entrances, there is no returning, and, in some places, great numbers are taken. The top and four sides of this net have entrances set in their area, as near the middle of each as may be, after the manner of the tail-hole of the Horse Net (see Horse Net), and a valve is sewn or netted round the orifice pointing inwards, and furnished with reans, as the valves of the Hoop or Eel Nets. The reans to be tied together and to meet in the centre of the interior of this cage or cube of net-work. 
No. 10. - Herring and Mackerel Nets have already been alluded to, under the head "Of Joining," as affording instances of the extent to which that process is carried, and of the importance which a thorough knowledge of it is to the fisherman. These nets are so simple in their construction, that little more remains to be said in this place. The Herring Net is made of fine twine. The size of the mesh is about one inch and a quarter square; the rands are joined to each other as before described, and the nets thus formed are afterwards tied at their ends to a considerable extent, as occasion may require.

The whole length of netting is suspended by its upper edge from a thick rope, called a drift-rope, by short and small pieces of rope, called buoy ropes, at about every tenth or fourteenth mesh; floats are tied in the ordinary way, along the top of the nets, but no leads are used for the lower margin. These nets are always shot during the night, as it is supposed the fish are alarmed when they see them and desert the ground immediately. The rands are all "dead net" in the Herring as well as in the Mackerel Net.

The Mackerel Net differs only from the former 
in number of rands and size of mesh, and in being made of still finer twine. The mesh of the Mackerel Nets being about one inch and a half square; they are shot at night, as the others, and the meshes are made large enough to admit the Mackerel, as they rove in the dark, beyond the gill cover and pectoral fins, but not large enough to allow the thick part of the body to pass through, so that the Mackerel hangs in the mesh, unable to advance or recede. Small casks or barrels are often fixed along the drift rope, not so much to assist in floating it, as to prevent losses in case it, and the lengths of the net attached, should get severed; the barrels indicating the place to the fishermen where the nets are, if he or his partners go in search of, or fall in with, them at sea.

Physiologists tell us that animal bodies are continually undergoing change in all their parts, and that, after a lapse of years, no single particle exists which belonged to the body when the animal was born; so it is with the Herring and Mackerel Net-after the lapse of three years, the Herring Net is not the identical engine that was turned out of hand thirty-six months ago-not a mesh is the same; by the gradual process of waste and 
renovation, as explained at p. 49, the original net has been removed and replaced in the order of the rands, yet it is to all intents and purposes the same machine-" aliusque et idem."

No. 11.-The Horn Net greatly resembles the Trammel. It has only one walling and the lint. The meshes of the walling are about four inches square, in strong and stout twine. The meshes of the lint are about one inch and a half square, but the thread is very fine though strong. The walling is made fast as usual to the rope, which is furnished with floats, along its upper margin; to the leaded rope along its lower margin; and down the ends, to the side ropes or bindings. The Lint is made double the length and double the depth of the walling; it is made fast below to the leadline, and along one end, like the lint of the Trammel, to the side rope or binding; but the upper margin is only suspended by means of large horn rings, which give the net its name, fixed to the meshes along the margin at certain distances, say about four inches apart; these rings travel on a loose line running parallel to the float-rope along the whole length of the walling, to each extremity of which it is fastened; by this contrivance, 
and with the additional aid of a string, the fisherman can, at any moment reeve up the lint into pockets or folds. To effect this, the other end of the lint must be allowed freedom as well as the upper margin. This is, in truth, nothing more nor less than the principle of the window curtain; the line on which the horn rings travel answering to the brass rod on which the curtain rings slide; and the additional string which the fisherman holds in his hand, ready to reeve up the lint withal, is simply the string by which the curtain is drawn on one side.

Owing to this net being made of very delicate material, the fisherman who is practised in the use of it, can feel the slightest vibration, caused by even the smallest fish striking against the lint, and is thus enabled immediately to secure his prey. Salmon, and all kinds of fish are caught by this manœuvre.

No. 12.-Eel Nets are made like the Bow or Hoop Nets already described, only very large occasionally, and with many valves. Sometimes they have wings and pixs, as the drag described farther on. The meshes are full two inches square, of thick twine. Leads and floats are fastened along the 
upper and lower margins. The Pix answers much the same purpose in a net as that part of a lady's gown, called by our Maradan's and Lewis's, a gore, does in dress-making. The wings in nets act as conductors, to guide the fish or fowls into the body, purse, or bag of the machine, as the case may be, and hence, in some instances, they are called leaders.

No. 13. - There is a kind of net much used on the canals in Holland, and on the Seine, at Paris, called by the French a Carreau or Echiquer. I have never seen this net in the hands of any English fisherman. The construction is very simple, being a piece of dead netting, varying from six to eight or more feet square. It should be strengthened along each margin, by having a cord, not very thick but strong, sewn round. The meshes are sometimes made smaller in the middle of the net than those nearer the outside. The best way of effecting this, is, perhaps, to net a piece of dead netting, of sufficient quantity, on a small spool; and then, with a larger one, net several rows round, as you would in making a bag, or landing net, taking care, however, not to go round so often as to make it too deep, but only set in so 
many rows with the larger spool as will make the machine somewhat hollow or pursey. For minnows the middle meshes must be very narrow, but it is better to have a separate net for the very small fish, than to make one size serve for all purposes. An engine of this kind should have the meshes as wide as circumstances will allow, inasmuch as it is important, in this mode of fishing, that the net should be withdrawn from the water as quickly as possible; and it is, perhaps, unnecessary to remind the reader, that the larger the meshes are, and the finer the twine, and the less compact or dense the net is, the less weight of water will be imbibed, and the less will be the resistance in every way, to the speedy rising of the net from the river or canal.

Some of these nets are faulty in this respect, that they are not made dished enough, being stretched out, so as to present almost a plane surface; the consequence is, that a fish of any size easily leaps over the sides back into his native element; but, by making the lint baggy, this disappointment is prevented. The depth of this pocket-shape is increased, according to the estimate which the fisherman makes of his power to withdraw the net with quickness and dispatch. 
At each corner of the net the cord which binds the sides is bent into an eye, or loop, for the reception of the ends of the curved rods to be now described.

The net finished, take two rods, or sticks, of any pliant wood, each stick to be almost half as long again as the diagonal measurement of the netting; these are to be curved into two arches, or half ovals, and each is to have its two ends fixed into the two eyes of the net which are diagonally opposite to each other. Thus, the two rods cross, and, at the point of intersection, they are lashed together by means of some strong twine or cord, and the same cord or twine binds the whole machine to another pole, made as light as may be, and more or less long, according to the depth of the water, and the distance which there is from the river's bank to the spot where the net is to be plunged. Again, sometimes the net is suspended from the pole by a longer or shorter piece of cord, according to circumstances; or, at other times, the end of the pole is lashed firmly to the cross pieces, without allowing any fall.

The fisherman chooses a situation where the current is slack, or where the water is warmed by 
the rays of the sun, or else where there are most insects sporting and playing on or about the surface; for here will the fish be gathered together in shoals.

The net is lowered deep into the water, and the fisherman watches his opportunity, when the fish, having recovered any little alarm occasioned by the plunging of the net, congregate again at the place and over the sunk net; he then draws up the net with the utmost expedition, for as soon as the animals perceive the motion of the wooden cross-pieces, they sink, and thus precipitate themselves into the toil; but the instant the latter is drawn upwards and quits the bottom of the water, they leap and dart off, and succeed in their efforts to escape, unless the fisherman be quick in his movements. This net is more fitted for, and is, therefore, more commonly used in shallow waters, whence it is more promptly withdrawn than in deeper places. Of course the fish has more chances of escape the longer the net is in being hauled up; hence the greatest attention must be paid, both to the structure of the machine, so as to make it offer the smallest possible resistance when being raised, and to the most advantageous manner 
of applying the power of the fisherman, so as to combine rapidity with caution.

This mode of fishing being more successful in thick or muddy water than in a clear stream, the fisherman generally selects the former for plunging his net into, but, inasmuch as he cannot then see the fish as they swim over the net, he lifts it up occasionally at a venture.

No. 14.-I met last year with a French book, entitled Découvertes dans la mer $d u$ Sud; before returning the work to the Library, I had an opportunity of taking a note of some nets made and used by the natives of one of the South Sea Islands. One of the nets resembled the Echiquier or Carreau of the French, as above described; it was, however, much larger and deeper. The net appeared to be quite as firm and as well made as any the author had ever seen. It was fourteen or fifteen feet long, more or less. Through the upper row of meshes a reed, or an ash stick would probably answer the purpose better, was inserted, and bent into a shape as nearly circular as possible, having the extremities lashed together.* This

* Ash is, perhaps, the best material for making hoops with, in all nets, and wherever else any thing of the kind is 
hoop again was plentifully furnished with pieces of rushes and bamboo, so that when one plunged it into the water it rose again with considerable velocity. At certain intervals, along the lower rows of the net, small pebbles were tied to the meshes by means of pieces of thread made from the fibres of the aloe or pine-apple plant, weighing only as much as was necessary just to keep the net from floating horizontally on the surface of the water; and besides these, in order to keep this bag in a perpendicular position, a moderate sized stone was put into the bottom of the net.

Two strong cords, attached to the circumference of the hoop, traversed the circle diametrically, forming with each other a cross; from the point where these cords intersected each other, was suspended a little net-work bag or purse, filled with pebbles, and being of sufficient weight to plunge the hoop into the water, and retain it at a certain depth.

required. Ash sticks are tough, pliant, and strong, though perhaps rather heavy. It has been suggested by a competent authority, that a recent melancholy accident with a parachute would not, in all probability, have occurred, had Mr. F. Gye's advice been adopted, of having the hoop of that machine made of ash instead of tin. 
Another cord, about the size of a child's little finger, and from four to five feet long, was tied by one end to this little loaded purse, and by the other to the extremity of a stick of a convenient length which the fisherman held in his hand, and by means of which he could, at pleasure, raise or lower the load of pebbles contained in the little purse.

To this cord was fixed a line about three or four feet long, from the extremity of which floated a little bit of light wood; to this line small lengths of thread were tied at certain distances along its whole length, to each of which a worm was tied by means of a knot; which expedient answered the purpose of hooks.*

* The account does not say whether the bait was alive or not. However that may be, in uncivilised societies, let us hope that British Anglers will save from obloquy their otherwise harmless, rational, and philosophical pursuit, by abandoning, as many have, the cruel practice of impaling live worms, and other poor creatures, on their hooks, there to writhe in agony, and to be nibbled at, and devoured piece-meal before death terminates their unnecessary sufferings. As to the Fish, there is not, perhaps an easier death to any animal which we procure for food than their's, when taken by the true disciple of IzaAK WaLTon; the hook passes through the cartilaginous portion of their mouths, 
Immediately that the fish, attracted by the bait, began to nibble at, or swallow, the worm, which was quickly perceived by the fisherman, from the motion which was communicated to the float, he lifted up, as rapidly as possible, the bag containing the pebbles; the hoop, now no longer kept down by any weight, rose to the surface of its own accord; and the fish thus surrounded was easily taken in the net.

The same author tells us that these Islanders have another sort of device, which procures them a plentiful supply of fish. This net is so large that he supposes it to belong to more than one where very little sensation, if any, resides; they come to the bait in a state of actual enjoyment, and are killed the moment they are landed; they are not chased and driven to their death, or teased and worried, for hours perhaps, as those are who fall a prey to the voracity of their fellows amongst the finny tribe; nor are they exposed to the still more lingering pains of protracted disease.

It is almost unnecessary to say, that, when talking of the unexpected transition from a state of animal enjoyment to the extinction of life among the brute creation, one must not be supposed to argue in the same tone as if he were speaking of the case as it stands with reference to human beings; in the latter consideration, moral reasons come in to change the whole complexion of the argument completely and entirely-it is the difference between time and eternity. 
family who unite into a kind of company, or jointstock proprietorship.

It is, in shape, like a large bag, being about three hundred feet in width, and long in proportion; so that one may easily imagine that its bottom and mouth are immense. When they set it, they go down to the beach at ebb tide, and select a spot which shall be completely covered at flood. They then set their huge bag with its opening towards the land, weighting the lower part, or lower leaf* of the net with stones, which is thus kept down on the shore; and besides this, they fasten it down with stakes driven into the ground. To the upper part, or upper leaf of this monster, they make fast a quantity of light sticks, and such other pieces of buoyant substances as chance may put in their way; and they take care to give sufficient play on each side of the net, so that the same -may open and shut freely. When the tide rises, the light sticks and floating bodies rise with it, and lift up the upper surface, or blade, or leaf, of the bag, and thus the machine remains open as long as the tide is up; so soon, however, as the latter recedes, the net collapses and is

* See Trawl Net. 
closed, and the fish, which are in it are secured without trouble.

No. 15.-The Drag Net. So many different nets are called by this name, that it is at times, or rather always, difficult to know which is meant. One kind is like a Trammel, only made in much stouter twine. Another resembles more the Salmon Net, which will hereafter be described.

No. 16. - The Salmon Net consists of four pieces - two wings, the bag, and the walling. Each wing is of equal size, say 150 meshes long and 100 rows deep, on an inch-and-a-half spool, The bag, or body, which occupies the space between the wings is netted on the same sized spool, but it is otherwise in every respect double the size of each wing; i.e. 300 meshes long and 200 rows deep. Here are three separate parts completed; we must now join them together in their relative positions. The wings must be united to the bag on either side of the latter, along their depth; but the bag is twice as deep as the wings; therefore two meshes of the bag must be taken up at once. The mode of joining* in this case must be either

* Nets of this build are used for other purposes besides Salmon fishing, modified and altered as occasion requires. 
according to Sect. 1 or 3, Note $X$. The bag is now formed by this process of joining. Fig. 18 represents a posterior view of the wings and bag.

The upper margin, A. B., is to be made fast to a cord with floats, as directed in No. 2 of this Note; and the lower margin, C.D., is to be made fast to a cord with leads in the same manner; viz. first thread a line of thick twine through all the marginal meshes round the four sides of the net, and then make fast the cord furnished with floats for the top, and leads for the bottom, and without either for the sides, to this line by whipping pieces of twine two or three times round the cord and line, embracing both firmly together at about every sixth mesh; or in any other way which the netter may prefer whether previously described by me or not.

\section{A piece of walling extending only over the mouth}

The wings may be set on by being netted in with the bag, and by making the length of the rows of the wing according to the depth of that part, i.e. netting rows from $A$. to $C$. and $B$. to $D$., instead of from $A$. to $a$. and $b$. to $B$., and then taking two meshes of the body or bag up together. In this case, the bag or body must be netted in the same direction as the wings, i.e. in its depth and not in its length; and the net must be bridled. See Note VI. 
of the bag, is next to be made and adjusted. The meshes of the walling to be about one foot square; and this member of the net is to be placed over the entrance of the bag, by being bound to the upper and lower cord, viz. to the lead line and float line, as the walling of the trammel is to its lines.

Different net-makers adopt different modes of mounting; each, I have no doubt, have their merits; I pretend to no infallibility, but simply state the system which I have pursued, leaving others to do as they please, without arrogating to myself the power of a reticular dictator, or absurdly laying down the law with a " sic volo, sic jubeo, stet pro ratione voluntas."

No. 17.-Another sort of Drag Net is composed of the purse, the pix, and the wings. The purse is netted round and round, and may be begun either at the tail end and enlarged towards the mouth, by having four false meshes set in at every third row, until the net is increased from three score and ten to eight score and ten meshes in circumference; or vice versâ, by beginning at the mouth, and diminishing from an hundred and seventy meshes to seventy, by means of stole 
meshes. In either case, the purse must have several rows of meshes in double twine towards the extremity of the tail, through the last row of which a small cord is threaded, to tie up the hose at its extremity. This is untied when the fisherman wants to examine the contents of his net.

The pix is a piece of netting of this shape (fig. A.) The row at $b$. consists of six loops; three

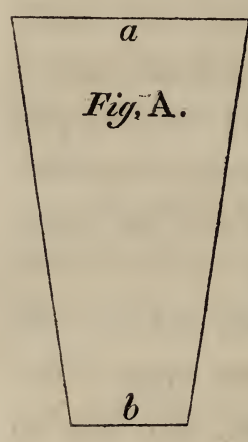
rows more are to be netted dead, and then a false mesh is to be set in at each alternate row until the side $a$. is forty-eight loops wide; the whole number of rows must correspond with the number of meshes in the row $a$. The row at $b$. must be in double twine. Two pix-pieces must be netted of the same dimensions, and joined on along the margin $a$. to the circumference of the mouth of the purse, $M$. at opposite sides, leaving an equal space along the circumference of the purse between each pix, $P$., on the right hand and on the left, consisting of thirty-seven meshes. See fig. $B$. 
The wings, $W$. $W$., are next to be made. Each wing is to be as deep as the side $C$. fig. B. of each pix, together with the intermediate space of the purse, which consists of thirtyseven meshes.

Each wing is joined on along its depth, at one end of the wing to the margin $C$. of each pix, and along the intermediate thirtyseven meshes,

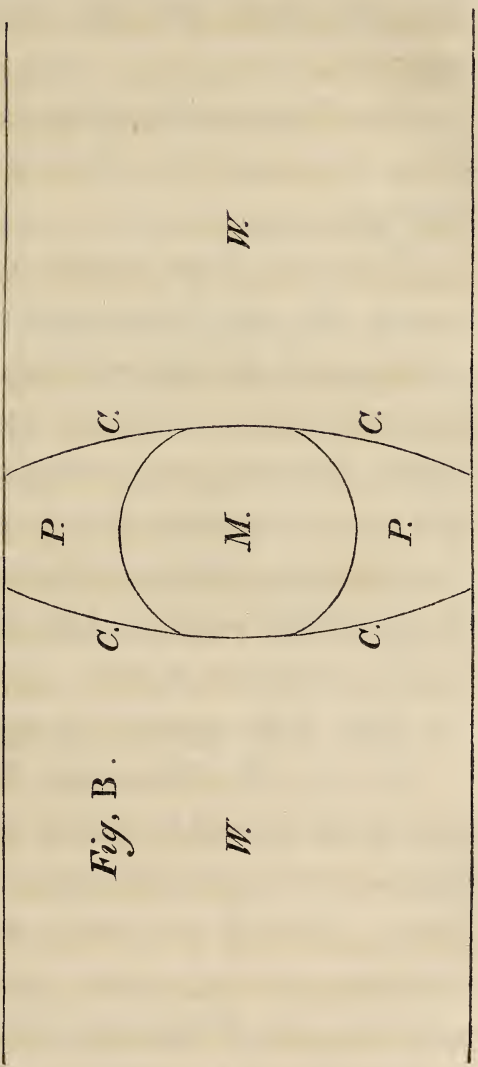
which extend between each pix on the right hand and on the left. The upper and lower margins of the wings to be of double twine for one row.

In some nets the length of the wings is greater 
than in others, but that depends on circumstances.

The Drags are fitted up with floats and leads along their upper and lower borders, but have no wallings.

The size of the meshes depends upon what service the net is intended for, and upon the strictness of the laws and their administrators, in particular places. I have seen the meshes very small; but there was no disguise after the parties had once ascertained that I was not a spy of the legislature, sent down to inform against and reform the piscatorial abuses of long standing.

Drag nets are, in some places, called Driggles, or Draft Nets-perhaps Draught Nets.

No. 18.-The White Bait Net being an illegal one, as far at least as the lex scripta is concerned, ought not to be particularly described in these pages. It is of two kinds, as to shape, but the smallness of the meshes being essential to its existence as a White Bait Net, must always give it somewhat of a smuggling character, especially as it is used on those parts of the river where the enactments against poaching are most properly and vigilantly attended to; but "quid non mortalia 
pectora cogis oris sacra fames ?" Nobody seems able to resist White Bait! It is a licensed engine by common consent, though not perhaps by common-council.

Recent observation, however, respecting the habits of the White Bait, reconciles all these apparent anomalies, and science comes to rescue our senatorial bon-vivants from the charge of inconsistencies; "for," says Mr. YARreLL, "since "the history and habits of this species have been " better understood, and it has been ascertained " that no other fry of any value swim with them"which I can aver-the men have been allowed " to continue this part of their occupation with "little or no disturbance, though still using an "6 unlawful net."

This " unlawful net" is either a diminutive Drag Net, with purse, pix, and wings, as described under the head of Drag Net; or else is simply a purse, measuring about three feet square at the mouth, and diminishing towards the tail, as the purse of the Drag Net aforesaid. The mouth of the net is fixed to a square wooden frame, and the engine is used as described and figured in $\mathrm{Mr}$. YARRELL's British Fishes. The meshes are 
rather larger at the mouth, but soon become smaller towards the tail, being scarcely so much as threequarters of an inch square.

No. 19.-The Tunnel Net is a kind of net, much used in former days, but not now, for catching Partridges; thus called from its form, which is a cone fifteen or eighteen feet long; resembling in general shape and mode of being netted, the valves of the Eel Nets, Bow Nets, \&c.

This net must be made of three-twisted thread, and must not be too thick; it may be dyed green, that the colour may deceive the birds and create no suspicion. The meshes should be about two inches and a quarter square. Into the last row of meshes, at the larger end or mouth, there must be inserted a smooth wooden rod, about the size of the end of your little finger; this must be bent into a sort of semi-circle, both ends being tied together, as in Eel Nets; and as in them so in this, must be placed hoops of wood, at different distances from one another, diminishing in diameter from the first to the last towards the tail, and supporting the net along its whole length in the tunnel form. Two strong pegs must be fastened at the sides of the entrance into the tunnel, and 
one at the farther end or point of the cone; the two first are to keep the mouth of the net sufficiently extended, and the last is to keep it pulled out lengthways to its full dimensions, the hoops preventing any collapse of the engine at any part. To the mouth of this net are to be attached wings or halliers. These are long pieces of dead netting extending seven or eight fathoms on each side of the entrance, so as to include a space of fourteen or sixteen fathoms in front, besides the breadth of the net's mouth, and to direct all that shall move forward within that compass into the net. In order to use this net, a covey of partridges is to be found, and then the net is to be placed at a considerable distance behind them; when this is fixed, the fowler is to fetch a compass and so get before the birds with a stalking horse, or stalking ox, and then to move forward, driving them towards the net; this is to be done gently and carefully; they are not to be driven at once straight forward, but the fowler is to wind and turn about, and, at times, to stand still, as if the horse or ox were grazing. If the Partridges, in the time of driving, make a stand and look at the engine, it is a sign they suspect it, and are ready to take wing; in 
this case the fowler is to stand still, or even to back a little; and when they are becorne composed again, he is again to advance upon them. If any single bird lies remote from the rest, the fowler must take a compass round him, and fetch him in, for if he takes wing the rest will all follow. In this manner, with patience and caution, the whole covey may be driven, like a flock of sheep, up to the nets. A real horse trained to the purpose is, however, much better than a stalking quadruped. The halliers or wings of the tunnel must not be pitched straight, but in a sort of semi-circle, and the birds, when they stop their march, will run along them to the middle, where the mouth of the tunnel is open.

When they come to the mouth of the tunnel, th old ones will make a stand, as if to consider what is before them; but, on pressing gently on them with the horse, the young ones will run in, and then all the rest will follow.

The fowler must then make all the haste he can to the mouth of the net to secure them from coming back again.

No. 20.-A common Net for Fowling is merely a piece of dead netting, about 90 meshes wide and 
125 rows long, on a spool about two-and-a-half inches circumference. Two long pieces of any pliant stick are bent at the top into two half arches, and each is retained in its proper position by a stout string, $a . b . a . b$. fig. 27 made fast at $a$. and $b$, and $a$. and $b$. The two sticks have a leathern hinge, so that the leaves shut up together at pleasure. The last twenty-five rows of net are turned up and fastened at $d$. e. The last row being threaded through with a piece of stout twine and. fastened at those points, thus making a pocket.

But a Fowling Net, of very superior construction and efficacy has been invented by Mr. Arton, of St. Andrews, Norwich, which seems likely to supersede the use of all other specific Fowling and Game Nets, as being capable of being used for general purposes, as I have already observed.

No. 21.-A Horse Net* may be made thus, admitting of any variety, in point of size and shape, which expediency may suggest:-Net 100 loops on a one-and-a-half inch spool, 115 rows of dead net; begin to diminish at the 116 th row by setting in a stole mesh at the end of each row. At the

* As represented in fig. 30 is not made mesh for mesh as here described. The cut gives merely a general view. 
120th row make the tail hole; for this purpose, begin the row as usual, stop in the middle and turn back; net again to the division and back six times, and each time you come to the division, $d$. fig. 30, take up two meshes at the end of the row; after doing this for six times, then increase the rows at the division, by netting twice into the last mesh of the row above; thus half the tail hole will be finished; repeat the same for the other half; then net across again in continuous rows, as before. Keep diminishing all this time at the sides of the net which are to hang along the horse's flanks, until you have diminished in all from the time you began twenty times on each side. Then net one row on a two-inch and two-eighths spool along three of the four sides of the net, omitting the upper side, or margin $m$. fig. 30 . Then four rows along the same sides on a one-inch and three-eighths spool. Then two rows on a two-inch spool. Then a row on a two-inch and two-eighths spool. Then two rows on a two-inch-and-a-half spool, taking up two meshes into one, or at once, whilst netting the first row. Add tassels afterwards at each mesh, which is done by looping fasces or bundles of the silk or other material of which the net is 
made into the loops of the last row of net-work; the length of the tassels may depend on the taste of the workman-say three or four inches.

Chain Stitch work is generally run along and interwoven with the net round the body, or that part of the net which is contained within the ornamental border formed by the lateral rows.

Many Horse Nets have no tail holes, and this need not imply any incapacity on the part of the manufacturer, but rather his caution, as there are many horses which are strongly opposed to such orifices.

No. 22.-Ear-Net, for Horses.-Net on a spool, about eight-tenths of an inch circumference, according to the nature of the material used, seventeen rows of dead netting, twenty-four meshes to the row. At the eighteenth row net only twelve loops and go back, and go on thus for fourteen rows. Repeat the same on the other side of the net, which will thus be, as it were, divided into two parts, like the skirts of a man's coat. Then net straight across, which will unite the two pieces at the bottom, leaving an orifice thereby above; then at the end of each row, or at two or three meshes from the extremity of each row, set in a 
stole mesh, until you have reduced to two meshes. Then work on from the other end of the dead netting; netting only twelve loops, and go back; thus for fourteen rows. Repeat the same on the other side of the net; and go on as you did at the former end. You have now got a piece of network pointed at each extremity-an oval, in factwith two slits or orifices in its surface. Net round and round each orifice, seventeen rows of dead netting. In the eighteenth row set in four stole meshes, and so at every fourth row, till the Ear $B a y$ is reduced to four meshes. These are tied up at the end, like the tail of many fishing-nets, with a long string and tassel. I say long string and tassel, because the action of the horse's head keeps these revolving perpetually, and therefore, if made about six inches in length, the flies are more effectually scared from approaching the animal. The Ear Net is bound with chain stitch work round the margins, and round the larger mouth of the ear-bags, where they rise from the head-piece.

No. 23.-A Hay Net is so called from its forming a hedge (une haie, in French) against rabbits. It is a plain length of dead netting, but it requires 
care in setting it up, for if hung and stretched too tight, the animal rebounds from it and escapes; if too loosely extended, he can get free of the meshes and run off; but, by a proper disposition, the net bags and entangles the animals, neither allowing him to re-bound or shake off his trammels.

In the Ashmolean Museum, at Oxford, there are some curious specimens of nets and netting needles of other countries. The figures refer to the catalogue of the Museum last published.

No. 197, is a curious Netting Needle (see fig. 29 in the plates of this work), from Otaheite, made of bone, presented to the Museum by the Rev. A. Bloxнam, of Worcester College.

No. 354, an Esquimaux Netting Needle of wood, is made precisely like our English ones without a tongue, but forked alike at each end. The specimen in the Ashmolean Museum is very long, being one foot six inches, and made of half-inch stuff. Presented by Captain BeEchey, who also has, amidst many valuable articles, presented to the Museum

No. 385, a curious Fishing Net with very large meshes, made of the intestines of the Walrus, and 
used by the natives of Port Jackson. The knot is constructed like ours, and the material has much the appearance of a dried, hard, old boot lace, such as the labourers fasten their high-lows with in this country.

No. 368, is another specimen of foreign reticulation, presented by the same distinguished officer; this is a whalebone net, used by the Esquimaux, N.E. of Icy Cape.

No. 231. $a$. is another donation of a liberal contributor to the same Museum-The Rev. A. Bloxнам-a Fishing Net of the South Sea Islands. This is a very elegant net, made with great neatness and regularity, and the knot resembling that of our nets. The workmanship would have done credit to the establishment of an EDGington or a Thacker. The length of the net is thirty-two feet, by two feet six inches deep; meshes lozengeshape, about half an inch square. The material of which the net is composed is a strong but fine twine, two-twisted. To the touch it is dry, harsh, and hard; but there were no indications of the meshes cracking or rotting. Floats are tied at about every four inches along the upper margin. Each float is, in shape, somewhat resembling a 
bit of a tobacco pipe, rather thicker and not hollow, about three inches long, made of some very light wood. Stones serve for leads ; these are small and tied on firmly and ingeniously, and in sufficient numbers to answer the purpose. Two rows of loops, in much stouter twine, are netted all round the net, to strengthen it at the four margins.

An Esquimaux Net, from Cape Thompson, (Capt. BEECHEY,) is another specimen of foreign manufacture. The material of which it is made resembles bass. The net is twelve feet long by eleven inches deep. Meshes very large; no floats or weights.

Another Esquimaux Net, fifteen feet long and seven feet wide, worked on a three-inch spool, is remarkable from having floats of some very buoyant wood attached along the upper margin of the net, and shaped like a small French roll; they are placed "longo intervallo" between each other, so much as two feet eight inches, more or less, of net intervening.

An Esquimaux Landing Net, presented by $\mathrm{R}$. Forster, Esq., another generous supporter of the Ashmolean Museum, is, in truth not a net, but a sieve, with an oval frame of bone surrounding it. 
It has a very long pole fixed to it, with which the fisherman wields his weapon. It resembles altogether a tennis racket.

All these nets are well wrought, but it is all dead netting; and they present no attempt at stole meshes, or quarterings, \&c.

This little book not professing to give a minute description of all nets used, whether in sea or river fishing, or in fowling, or for all the various purposes to which reticulation has been, is, or may be applied, a few examples have been deemed sufficient to shew the application of the instructions given, or attempted to be given, as to the management of the spool and needle, the treatment of nets, \&c.

The reader will find more general and more numerous descriptions of nets in other works, where these minutiæ would have been misplaced, but a knowledge of which will enable one to work from those general descriptions, and to understand more technical particulars when he meets with them; as also to trace with facility the mode in which any net submitted to his inspection is constructed.

Before I conclude these recipes, I shall add one 
or two respecting another, and more ornamental department, of netting. We have discussed and decussated twine and rope sufficiently; and having put them by on their respective shelves, and shut up the spools in their trays, let us get a few reels of Persian thread, very delicate and fine, and a few steel pins (not spools now), and set to work in making

\section{I. - A Lady's Cap.}

Net eight rows, containing seventy loops, on a pin three-eighths of an inch circumference; one row on a pin half an inch in circumference, netting three loops into each mesh; eight rows on a pin two-tenths of an inch in circumference; one row on the half-inch pin; five rows on the three-eighths, in netting the first of which five, take three meshes up at once. And so on, making in all seven sections of large meshes, the first and last to consist of eight rows on the three-eighths pin; and six sections on the smallest pin. That makes the body of the cap.

Now for the border. Net 700 rows, two loops to a row, on a three-eighths pin. Then work in a contrary direction, i.e. down one margin or selvage one row on a half-inch pin, netting three times 
into each mesh you take up. Then five rows on a two-tenths pin; then one row on a half-inch pin; then one row on a three-eighths pin, taking up three meshes at once and in coarser thread. Then run your foundation string along this last row, and work from the other selvage; net three rows on the two-tenths pin, one row on the halfinch pin, then six rows on a three-eighths pin, taking up three meshes at once in the first of the said six rows.

Next we have the Pole Border. Net 120 rows, five loops to the row, on a three-eighths pin. Work down the selvage on a half-inch pin, netting three times into each mesh. Then four rows on a two-tenths pin; one row on a half-inch pin; one row on a three-eighths pin, taking up three meshes at once, with thicker thread.

\section{II.-A Lady's Scarf.}

In persian thread or sewing silk, net three rows on a pin three-eighths of an inch circumference, 700 loops to the row. Twelve rows on a half-inch pin, and so on; making in all eleven sections of small meshes and ten of large. 


\section{GENERAL NOTES.}

Glomeramen in unum conveniunt.-LUCRET.

I.

IN giving written descriptions of nets, great care should be taken, when numbers are specified, to write the figures clearly; or, perhaps it is better and safer at once to spell the words at length. instead of using cyphers.

Not long ago an honest fisherman, whom I am in the habit of assisting in making his nets, wrote down his wants for my guidance; amongst the instructions contained in his receipt was this :"Increase to 10025 meshes in the row." Knowing for what purpose, and on what water, he was to use the required engine, I felt convinced some mistake existed, and upon meeting the worthy man I asked him if ten thousand and twenty-five meshes would not make the net deeper than might prove convenient? he seemed greatly sur- 
prized that I should think he had made so exorbitant a demand; he meant, as it soon appeared, an hundred and twenty-five, which he conceived would be expressed in writing by the above five figures, viz: the three first standing for 100, and the two last for 25 .

This reminds me of an anecdote which $I$ have met with somewhere that a gentleman having employed his workmen on some job, sent for their several bills as soon as it was completed, and very wisely put them into the hands of a certain surveyor to be examined, who, having retained them a reasonable time, but, as will appear, not having analysed the items very minutely, returned them all, with their several amounts cut down, in due form and order. The gentleman sent for his workmen, of whom the carpenter was first, and tendered him the reduced amount of his bill; the tradesman refused to accept it, affirming, at the same time, with the most provoking confidence and obstinacy, that his bill was a fair one, and that the whole was his just due. The gentleman paid him his whole charge, and informed him he should have no occasion for his future services. Some of the other tradesmen, whose bills were of less 
consideration, either because their conscience smote them, or acting upon the maxim, that the first loss is generally the least, when they heard of the dismissal of the carpenter, accepted the reduced amount of their charges, rather than lose their employer's custom. At length the smith appeared, who had been under very great obligations to the gentleman; and from his bill, apparently of $£ 30$. stood a deduction of $£ 6$. marked by the surveyor. The gentleman, after expostulating with Vulcan for his villainous ingratitude, as well as dishonesty, in attempting such an imposition upon him, assured him he should have no farther opportunity of exercising a similar conduct with respect to him. The smith humbly begged to know the reason? "Reason, sir, why Mr. Skinflint informs me here, you have overcharged me $£ 6$. in this bill!? "Why, sir, replied the swarthy artist, I am at a "loss to know how that can be, for my bill, as "your honor will see by the items, only amounts " to £3., and you say I have overcharged you $£ 6 . "$ After a little mutual explanation, the truth came out. The metallurgist was but a lame writer, and by an unlucky scratch of his pen, he had made the amount of his bill, which was £3., look so like 
$£ 30$, thinking that an 0 of course stood for nothing wherever it might be placed, that any person looking no farther than the total, might have made exactly the same mistake that the surveyor did.

\section{II.}

In charging your needle, take the twine from the inside of the ball. This prevents tangling, which is at once recommendation enough. When you charge the needle with double twine, draw from two separate balls.

\section{III.}

In Holland no person is allowed to exercise any trade, commerce, or profession, without being furnished with a patent or license. Fishermen, however, are, with one or two other callings, specially exempted from the restrictions of this law.

IV.

In the year 1776, the Salmon fishery on the River Ban proved extraordinarily successful. The take of one net at one drag was, in this season, 1452 ; the largest haul, I believe, on record. Mr. Young, in his Tour in Ireland, mentions the circumstance, but I have not the precise words of the author, nor any accurate reference to the passage, by me. 


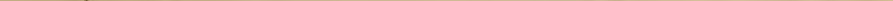


A Table shewing the distances of the principal Towns and Bridges on the River Thames and River Isis, between London and Oxford.

London Br.

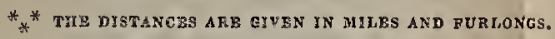

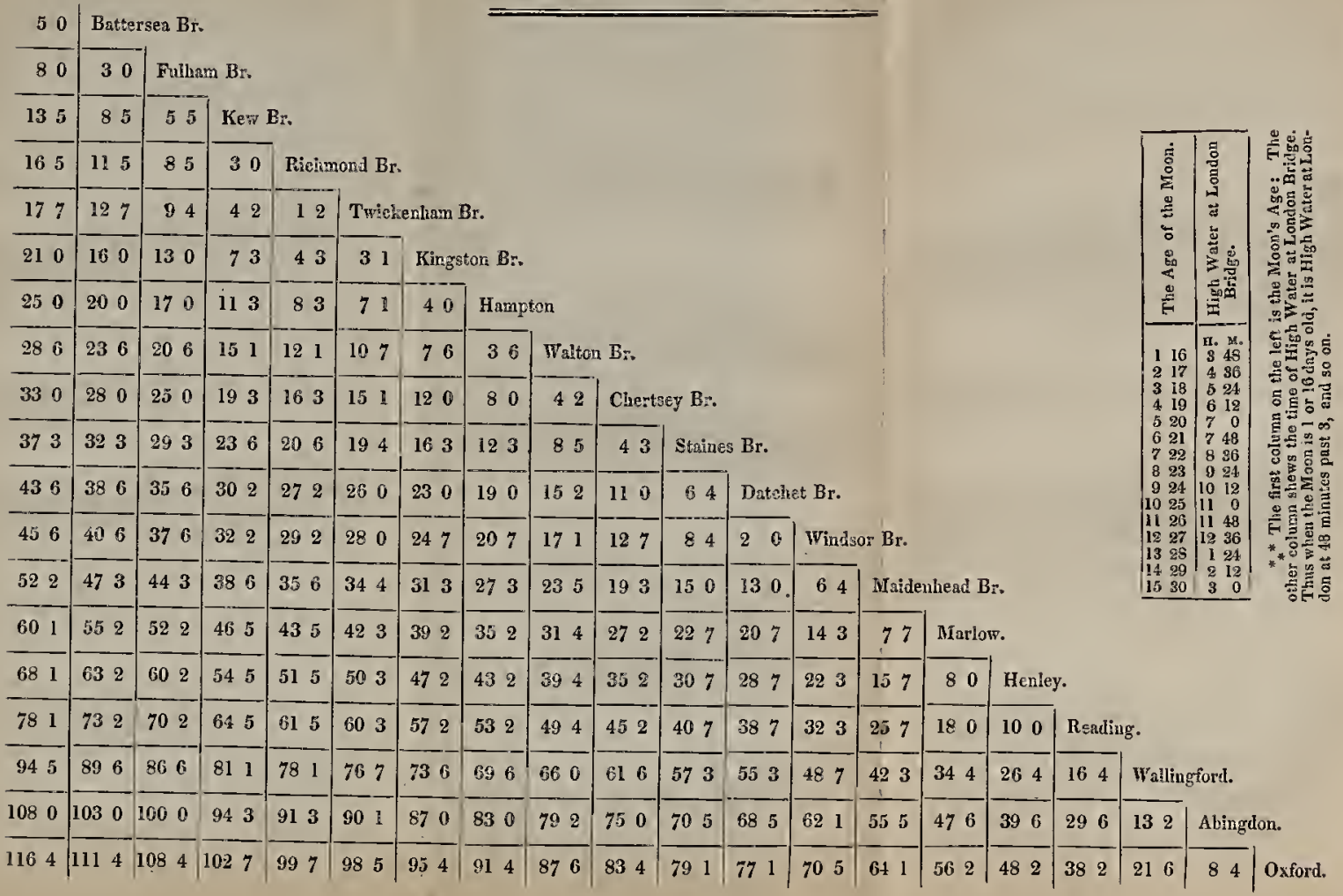


V.

The fil de pitte mentioned by some French travellers, is a kind of thread made from the fibres of a sort of aloe or pine apple, and according to which of the two the thread is made, it is called thread of aloes pitte, or ananas pitte. The plants grow in the West Indies, and answer the purpose of hemp and flax.

\section{VI,}

My friend Edward Jesse, Esq. has given in his last amusing volume, Angler's Rambles, a "List of the Deeps" between Chertsey and Battersea, for the use of his brethren of the WALTON and Cоттол art. For the farther guidance of fishermen, I now insert a Table of Distances from London Bridge to Oxford along the river. I am aware that it differs in some respects from other tables, but for reasons unnecessary to mention here, I have given this version of the matter. (See Table annexed.) I subjoin the following Notes :

Between London Bridge and Kingston there is one Lock, viz. Teddington Lock. Tide.

From Kingston to Hampton (town) one Lock, viz. Moulsey Lock. Stream stiff; but keep to the Thames-Ditton bank and it is easier.

From Hampton to Staines, four Locks:- 
Sunbury, Shepperton, Chertsey, Pinton-Hook. Stream stiff from Hampton to Shepperton Lock; easy afterwards.

From Staines to Maidenhead, three Locks;Bell Weir, Old Windsor, and New Windsor Locks. Stiff stream from Staines to Bell Weir. Easy for about two miles. Very stiff to Windsor afterwards, and from Windsor to Maidenhead.

From Maidenhead to Shiplake, seven Locks:Boulter's, Cookham, Marlow, Hurley, Hambleton, Marsh, Shiplake. Stream stiff near Boulter's Lock for about a quarter of a mile on the London side. Scenery beautiful all the way.

From Shiplake to Streatley four Locks :-Sunning, Caversham, Mappledurham, Whitchurch. Stiff stream near the London side of Mappledurham Lock, otherwise moderate.

From Streatley to Abingdon, six locks :-Goring, Cleeve, Benson, Day's, Clifton,Cullam. Stream stiff.

From Abingdon, to Oxford, three Locks :Abingdon, Sandford, Iffley. Stream moderate.

Total number of Locks between London and Oxford, twenty-nine.

Very little is known of the beauties of the Thames scenery by persons in general, from London Bridge to Oxford. It has often occurred 
to me whether, in these days of speculation and adventure, it might not prove a source of profit to the proprietors, and of agreeable recreation to the public, if a vessel, on the plan of the Dutch Trackschuyt, were to ply at stated times in the summer months between Richmond and Oxford; the Steam Vessel between London and Richmond bringing the passengers to and from the latter place. The downward-voyage cateris paribus would occupy less than half the time of the up-voyage. The Trackschuyt might lie to during the night, at such stated places as would be most convenient for the passengers to land at. As, of course, these vessels would be only employed for pleasure voyages, and would, at the utmost, carry only light parcels from one place to another on the banks of the River, in the shape of trade, they might be fitted-up with every convenience for passengers without requiring sleeping berths, or stowage for heavy goods. Such a trip of pleasure and recreation would, I conceive, be highly entertaining to the lover of pretty scenery, fishing, natural history, science, and the fine arts, net-making included!

The accommodation at some of the little comfortable Inns on the River are excellent, and I can speak from experience. Many a follower too, of 
"Old Master Izaak" will cordially agree with me, -it is well for us to agree where we can-though I fear they look upon a Net-maker with little less complacency than they survey an Otter withal, not to say, a Poacher.

\section{VII.}

Spring Gate.-"We had (in Norway) to cross a bridge, before which was a gate, the opening and shutting of which were simple and ingenious. A string led from the gate to the upper part of a small birch tree. When the gate opened, the birch being very pliant, bent with it; but when it was let go, the birch tree righted itself, and, of course, drew the gate with it."-Barrow's Northern Excursions, $p .326$.

I have tried a gate on this plan at Siddington, and find it answer admirably, to say nothing of the surprize it occasions to one or two old men and women who have occasion to use it. The gate is net-work, of strong cord, stretched on a wooden frame.

\section{VIII.}

The Rope-walk at the Dock-yard at Portsmouth is a quarter of a mile in length; the boys employed walk twenty miles a-day at their work. 


\section{IX.}

A Hood Net is sometimes, though erroneously, called a Wood Net. In Gloucestershire, on the other hand, the word wood is often pronounced hood. The dialect of this County is the most discordant and harsh that I have ever heard. Amongst other peculiarities, the lower orders call every thing he and him, be it man, woman, boy, girl, house, horse, seaman, or ship. Upon entering a cottage, one is somewhat puzzled occasionally to trace who or what is referred to by the speaker, and tempted to say to the husband with William, in As You Like It, "Which he sir ?" or to address the wife in the words of the clown in the same play, "All your writers do consent that ipse is he, now you are not ipse."

\section{X.}

Never throw away a piece of netting; it always comes in for some use at some time-either for experiments, or foundations, or the garden.

\section{XI.}

The dirtiest part of the net-maker's work is putting on the floats; this is worse than sewing on the leads, by a great deal. Cork-cutting is, I believe, universally acknowledged to be the dirtiest 
of all trades, and it appears to me the most uninteresting of all occupations. The cork is always burnt before it is cut, so as to remove all foreign matter from the surface, and to close up the pores, hence its blackness. The bundles of cork come to this country tightly packed and tied round with a peculiar kind of grass plaited together and forming a strong cord. The poor people buy, or have given to them, these cords, by untwisting which they make carpet-brooms, \&c. for sale.

\section{XII.}

Netting for fruit trees is made, I believe, by Machinery at the factory of Mr. BenJamin EDGINGTON. I do not know that any other nets have as yet been made for general purposes, or of any other description than plain or " dead netting." False meshes, or change of size of spools, have not hitherto been, as far as I know, effected by Machinery.

\section{XIII.}

Always have by you, ready for use, a few foundations, consisting of four or five rows of net-work, some few score meshes long, upon which to work; the work goes much smoother than when a string foundation is used. Remember 
always to net a waste row when you begin a piece of work on these, which must be cut away when you detach the new net from its original stock. Be particular in keeping your foundations clear of old knots, by picking them out before you put them to after use; hence they will always be fit for immediate service.

\section{XIV.}

Always use twine as fine as circumstances will permit. The thicker the twine is, the thicker will be the knots; and hence the net will be more likely to rot at these points by retaining the moisture. It is of great importance that nets should be thoroughly washed and dried after being used, and before they are stowed away. The same regard to cleanliness and drying should be observed with respect to silk nets; and with care, I am told, that the silk Casting Nets pay, by longer duration, the original extra expence of the material.

\section{XV.}

Spools made of Lignum Vita have a very beautiful appearance. They are turned at any Boat-builder's or Shipwright's on the sea coast.

\section{XVI.}

Turbot, when cooked too soon after being 
taken, is not so good, in point of flavour, as when it has been on shore a few hours. A celebrated fishmonger told a friend of mine, that he once lost a good customer owing to his having sent too fresh a fish of this kind, which the gentleman supposed was over-kept, or otherwise in bad condition.

If this note should meet the eye of my honest friend "JACk Sмгтн," let him not fear that he is likely to fall into this grievous error, or lose any customers by this precociousness. He is physically, geographically, and locally prevented getting his fish on his slab too soon, even should rail-roads expedite his basket's transmission. By care and attention, however, he may always have his fish in good condition. Verb. sap.

\section{XVII.}

In some nets, Cork Floats are placed between two small ropes running parallel with each other, and having twine whipped round them both, and tied, at each end of the floats; and so keeping the latter all firm, instead of their being loosely threaded on one thicker rope; and the two ropes thus furnished with floats, and lashed to each other at these points, and thus forming in fact but one rope, are not bound to the upper margin of the 
net itself, but short lines of equal lengths are fastened by one of their ends to the float-rope, and by the other to a mesh of the net,-one line to about every eighth or tenth mesh; and thus the net is kept suspended from the float-rope, as the Herring Net is from the drift-rope, along the upper edge of the net, at stated points.

\section{XVIII.}

Lime, sifted gravel, and coal ashes, equal parts of each mixed with water, make a good composition for the floors of Garden Houses, Fishing Huts, \&c.

\section{XIX.}

Sore fingers to a Tyro in net-making, bear some analogy to sea sickness in a young sailor; both by habit become insensible of the inconvenience; unless, perhaps when very hassh twine, and very rough weather induces a recurrence of awkward sensations. If the twine be extremely wiery and hard, it may be softened by boiling; but this is a somewhat unworkmanlike mode of proceeding, and is as one who prefers mounting aloft viâ "Lubber's Hole," not caring to trust himself to any other route. 

MISCELLANEOUS MEMORANDA.

o 3 


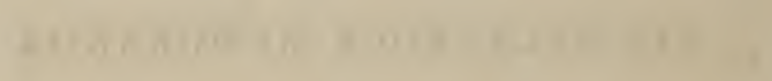




\section{MISCELLANEOUS MEMORANDA.}

History of Nature is of three sorts:- of Nature in course, of Nature erring or varying, and of Nature altered or wrought; that is, History of Creatures, History of Marvels, and History of Arts.-Lord BAcon.

\section{I.}

Unusual Structure of the first two Cervical Vertebre of a large Quadruped, found in a Bone-yard.

There is, perhaps, no opinion more prejudicial to the promotion of scientific knowledge, than the idea that trifles, when observed even by us unscientific men, are not worth recording or being examined. Some of the most splendid inventions and useful discoveries have had their origin from what might at first appear, to the careless observer, trivial occurrences, and, as such, unworthy of any analysis. It is by noting down any the smallest deviation from the more common contrivances and operations of nature (such as, for instance, 
any slight variation in the formation or habits of animated beings), that the ordinary observer, as well as the professed naturalist, at the same time that he gains to himself an endless source of amusement and instruction, can likewise hope to contribute to the support of science, and add a powerful stimulus to investigation; the final results of which, become, not unfrequently, of most extensive and permanent advantage to mankind. But, independently of this, supposing that such or such a fact leads to nothing beyond the knowledge of the bare circumstance observed, still it is an operation of nature, and, therefore, ought not to be passed over by the general observer, whose professed object is to record new phenomena for the purpose of still better comprehending the magnificence and beautiful order of creation, and of more worthily adoring its beneficent Creator. The case to which I beg to invite the attention of my readers, is one of unusual structure in the first two vertebra (verto, to turn) of the neck of some large quadruped, as exhibited in a specimen picked up at a bone-mill at Grimsby, some years ago, by myself. (Fig. 31.)

It will be proper to explain the ordinary struc- 
ture of these two bones in vertebrated animals, so as more clearly to demonstrate the extraordinary formation in the specimen referred to. When it is remembered that the object of the back-bone or spine is to give support to the whole frame; that at the same time it must be firm and flexible, so as to allow of free motion; its structure exhibits a most interesting example of adaptation of means to the end required.

The whole backbone consists of a certain number of separate bones, locking one within the other in succession, and moving on each other by means of smooth surfaces, which admit of a sufficient degree of play, at the same time that strong connecting ligaments prevent dislocation. Each bone or vertebra is in the shape of an irregular ring, thicker in front, which thicker portion is termed the body: processes, or bony projections, stick out laterally, obliquely, and posteriorly. It is from the shape of those which stick out behind that the whole column derives its name of the spine. The long series of these vertebræ, which extends all along the back, forms a tube or canal, nearly round, but rather flattened in front, for the reception of the spinal marrow, which is, in common 
parlance, without entering into any minute disquisitions on the point, a prolongation of the brain; and which, from the important offices it is destined to fulfil, and its extreme delicacy (the least pressure causing paralysis or death), requires to be as strongly defended as it is. On the top of this column is placed the head. Now, when we consider how necessary it is, for the preservation and comfort of the animal, that the head should have free play up and down, to the right and to the left, we shall be led to examine with wonder and delight the beautiful yet simple mechanism by which this is effected. The up-and-down (supination and pronation) is produced by a peculiar formation of the first cervical vertebra (fig. 32. $a$ ). This is termed the Atlas, because it gives support to the Globe of the head. It has, on its upper surface, cavities to receive the condyles (or knobs) of the occipital bone of the head: thus a hinge is formed, and the head acts freely in that direction.

But now we want horizontal movement; and for this end the second vertebra $(b)$ presents a peculiar mechanism. From the body of this bone a process, called, from its resemblance to a tooth, the procéssus dentàtus $(e)$, arises, and sticks up 
perpendicularly; and, fitting into a hollow in the interior surface of the body of the Atlas, allows of the horizontal action of the skull. Thus we have the compound action required, amply and beautifully provided for. Now, though in the structure of the spine of all vertebrated animals there exist some slight modifications suited to the habits of the different animals, the general type is uniform; but, in the instance of the two vertebræ now the subject of this notice, there appears a very essential departure from the general mechanism. Upon examining the first vertebra (fig. 31. $a)$, I found that the transverse processes $(c c)$, as well as the upper surface of the body of that vertebra, were hollowed out, in order to receive the condyles of the occipital bone: hence it would appear that this is the Atlas, and that the animal had the power of moving the head up and down. I next examined the second vertebra $(b)$. The tooth-like process is totally wanting; there are no traces of its ever having existed; there is no cavity in the Atlas for its reception; but there is a very curious bony excrescence which unites the two vertebræ firmly together on the left side $(d)$. The two vertebre are perfectly distinct and sepa- 
rate as usual, except at that one point. There are no appearances whatever of the second vertebra having been joined in a similar manner to the third, the under surface of the former being persectly smooth. What I would particularly remark in this specimen is, that whilst, in all the spinal columns that I have ever seen, Nature has (as it has been explained) provided in an especial manner for the horizontal motion of the head, she has in this instance made an especial provision against the possibility of such an occurrence. The lower cervical, the dorsal, and the lumbar vertebræ, are not wanted to move horizontally, and there is, therefore, no tooth-like process in any of them; but, on the other hand, they have nothing analogous to the bony excrescence which is observable in fig. 31, to keep them firm; the surrounding ligaments, \&c., are sufficient for the purpose. From the specimen I have described, it would almost appear that Nature had feared that the Atlas would instinctively try to move in a rotatory direction, as in the generality of cases ; and that thus an extra fastening was provided, for keeping the animal from attempting to imitate its neighbours, for which it had not the requisite apparatus 
with which they are furnished. Whether these vertebræ belonged to an individual of a species of vertebrated animals who enjoy but a circumscribed action of the head, or whether this be an instance of malformation, I do not pretend to decide. The fact is a curious one; and I do not remember ever to have seen a similar circumstance noticed in any of the works which treat of that deservedly admired piece of animal mechanism, the spinal column.

The dimensions of each vertebra are $3 \frac{1}{8}$ in. deep, and the diameter of the spinal canal $1 \frac{1}{4}$ in. The transverse processes are broken off at their extremities. I much regret that I have lost this specimen.

\section{II.}

A Tick which moved on a Diseased Part of itself. Some days ago, I extracted a tick from my dog, and flung it into a finger-glass of water. After floating for some minutes, the abdomen seemed to detach itself from the rest of the body, and the insect to move upon this discarded part of itself, as a man walking on a raft. The abdomen of the tick had been very much distended, and wore the appearance of one of those small leathern 
bottles in which oil-colours are sold to artists, only considerably less in size.

I have received the following solution of the inquiry respecting the above phenomenon from an unknown friend, whom I beg to thank.

" This appearance, in all probability, was only " a consequence of the pedicle, which attaches the "Thorax and Abdomen, being elongated by the "force applied in extracting it from its hold on " the Dog, and which enabled the body and legs " to turn and surmount the floating Abdomen."

\section{III.}

Extraordinary Phenomenon at Hastings, April 9, 10, and 11, 1837.

During the above-named days I observed, in common with hundreds of others, several Gurnards floating on the surface of the sea; and men and boys wading in about knee deep or deeper, pulled them out, without the fish apparently making any effort to escape. Upon inquiry I found:-

First,-That no other kind of fish than the Gurnard was thus rendered, from some cause, an easy prey to any person who chose to capture them, either by the hand or in a Landing Net. 
Secondly, - That the Conger Eels, and the Conger Eel only, a few years ago, when it was very cold at Hastings, were in the same predicament.

Thirdly,-That some of the fishermen attributed this helplessness of the fish to the fact of their being blinded by the cold, and hence could not see those who captured them, as they approached towards them in the water.

Fourthly,-That others of the fishermen conceived that the fish mistook the flakes of snow which fell, for insects, and leaped up so eagerly and frequently for the purpose of catching them, that " they blowed themselves ;" meaning thereby that they so distended the air-bladder that it lost its power of contraction, or its elasticity.

Fifthly,-That others, again, imagined that the fish were rendered senseless by the extreme cold, and hence were easily taken without offering any resistance.

I bought one of the fish just as it was taken from the water. The fish was not blind, the eyes being perfect. The fish was very lively, so far from being senseless; and all the other fish I saw were equally so, and I saw a great many handed 
from the water. Upon opening the abdomen, the air bladder was very much distended indeed, but it appeared as elastic as usual. Snow was no new thing to them, either in this or in preceding years, yet this phenomenon was not observed to have occurred before; at least there is neither remembrance or record of the fact, as far as I have been able to ascertain. The only circumstance analogous to it being that relating to the Conger Eels above-mentioned, which took place in the winter, but I could learn no particulars as to them.

At Brighton, Gurnards are plentiful, yet I did not find, upon inquiry, that any such appearance was remarked there; it seems, therefore, unreasonable to suppose that the Gurnards on the Hastings coast were less sagacious than their congeners elsewhere, and were so easily imposed upon by the snow on these particular days. May it not rather be, that the Gurnards were enticed into shallow water in search of food, and that the shallow being colder than the deep water, they became so benumbed as that when they had once distended the air bladder to mount to the surface, the muscles had not power to compress the bladder, and hence the animal could not sink and 
escape? just as a man unbuttons his great coat on a cold day, and when he attempts to fasten it again the thumb is weak and helpless.

The above having happened only at Hastings, so far as I could learn, is worthy of investigation; and I should rejoice to see some scientific Naturalist take the matter in hand.

\section{IV. \\ "Nature Varying."}

In the Museum of Dr. John Harwood, at St. Leonards, is a very beautiful specimen, amongst other interesting objects, of the process of reparation, as exhibited in an Elephant's Tusk.

The animal had been shot by a bullet, which had passed through the hollow part of the tusk, near the mouth, leaving two shattered holes where it entered and came out. The Elephant was killed before nature had completed the cure of this wounded part, but not before so much had been done as to render this one amidst ten thousand other beautiful instances, of the care which the ALMIGHTY takes of his creatures.

We must imagine to ourselves the hollow part of the tusk removed from the jaw, and presenting, 
when held up to the eye, the appearance of a tunnel; in the upper half, or roof, at $A . A$., are the holes made by the bullet. The holes at the animal's death were partially filled up by newlydeposited bone; but as this portion of the tusk must, of course, be greatly weakened, Nature had contrived a bony arch, beam, flying buttress, and inverted arch, to support the injured roof of the edifice. See fig. 28. The shaded parts are the newly-deposited bone, intended to give strength to the injured edifice; B.buttress; b. beam; $c$. arch; d. inverted arch.

\section{$\mathrm{V}$. \\ Another Instance.}

In the same Museum was also a large round ball, very hard, but extremely smooth and polished outside; it was found in the stomach of a horse; the ball was composed of very thickly compacted hairs, swallowed by the animal after licking his own and perhaps other horses' coats. Had the mass been left with a harsh and rough surface, it would have irritated the stomach extremely, and caused excruciating pain ; but, as it is, the smooth covering allowed the globe of coarse hair to move 
freely and easily upon the coats of the stomach, and the coats of the stomach to move over it without pain, or, perhaps with only very slight inconvenience.

VI.

The Game-keeper's Tradition.

The Black Cock.-There is a tradition among Sportsmen, that when the little Black Cock appears alone, it is not advisable to shoot him, inasmuch as he comes only as a spy inland; and returns, if left unmolested, to the sea shore, and conducts the flights of Woodcocks to the part of the country he has visited, when they arrive at the coast, should he have found a situation likely to suit his friends. If he is shot, therefore, the main body may perhaps go somewhere else.

\section{VII.}

The Angler's Tradition.

Some Anglers think that fish have the power of communicating their ideas, and of giving intelligence to each other, to such a degree as to make it an act of bad policy to fling a fish back into the water after he has been caught, lest he should go 
and caution all the rest against frequenting the same place.

\section{VIII.}

Ear-wig Traisformation and good qualities.

Mr. Jesse, in his deservedly popular work, Gleanings in Natural History, says, "Ear-wigs turn to Flies. This may easily be ascertained by developing one, after killing it, with a pointed pen-knife. The swallow-like tail will be discovered to be two terminations of wings." That Ear-wigs have the power of flying, though they are not often seen to exert that power, is very certain; and by a careful separation of the upper wings or sheaths, as noticed by Mr. Jesse, their beautifully packed wings are exhibited most clearly. But, if I have rightly read my friend Mr. Jesse's remarks in the above passage, that accurate observer of Nature means that the Ear-wig is not simply able to $f y$, but becomes $a f l y$, that is, changes from its own order to another,- that being a Coleopterous insect, it turns to a Dipterous insect, of the genus Musca; or, to use un-entomological language, the Ear-wig becomes from a four-winged complete insect a two-winged complete insect. If this be 
Mr. JEsse's meaning, I venture to differ from him on this subject of insect apostacy, and I do so without fearing that our friendship will undergo any metamorphosis from its present state.

My reasons for holding an opinion contrary to that expressed by the Author of Gleanings, are as follows:-The Ear-wig, in all its states and stages of existence, differs but little from the complete insect, as is the case with the Locust or Grasshopper tribe, and some others. It has no wings at first, but is very like the parent animal in other respects. The Fly or Musca genus is very numerous, and belongs to the order Diptera. Dr. SHAw says that some species of the Musca genus are Viviparous; but when this is the case, and when it is not, and whether the changes of the insect in its different stages be great or little, no matter;a young Fly and a young Ear-wig never becomes any thing else than an old Fly and an old Ear-wig. Nor has the perfect Musca, or the perfect Ear-wig ever been any thing else than one of the same cognate order in an imperfect state; just as the Colt becomes a Horse, and a Child a Man, and nothing else; and the grown-up Horse never turns to a Man, nor the grown-up Man to a Horse. 
The generality of the Musca pass through their three distinct states of existence, after the manner of Insects; instances to the contrary forming exceptions, and not the rule. It appears to me, from what has been said, that the Ear-wig no more turns to a Fly than the ends of two parallel lines meet.

The great dread of the Ear-wig entering the ear, is a popular error, whence, indeed, the animal derives its trivial name. Like many other insects, it enters any cavity in search of food or shelter; and it may, like them, enter the human ear as well as any other hole or hollow, but that it has a special predilection for that situation is a mistaken notion respecting the habits of the Forficula.

These poor creatures gain great discredit, and are rendered odious in the eyes of many persons, owing to this reputed enmity against, or too great fondness for, the tympanum of man: whilst the tender care and affection which the female, with truly feminine amiability, shews towards her young is seldom talked of, nor is it sufficiently regarded. But this is not the only instance of the eagerness we shew in magnifying the faults, and passing 
over the virtues, of those around us; "sincerum cupimus vas incrustare."

\section{IX.}

"The Old Eye."

At the Earl of Abingdon's Country-place, in the neighbourhood of Oxford, there is a rivulet which falls into the Isis, and to a particular bend of it, where it widens suddenly, the name of the old Eye has been given from time immemorial. I have heard many persons express surprize at the strangeness of the title, but I never heard a solution of the mystery, until I happened to see a History of Gloucestershire the other day; and under the heading "South Cerney," I found that the parish derived its name from Cern or Churn, the river which flows through Cerney, and Eye, an old Saxon word for Water. Hence, I conclude, that the Old Eye is the Old Water; and that it may have been thus particularly designated owing to the water being wider and deeper at that turn of the rivulet. The stream does not here form by its wanderings any thing like an Ait, or Eyght, or $E y o t$, or $E y$, or $E a$, or $E e$, or Eyet, and hence does not take its name from any of those words, 
or their Saxon derivation. Can it be, that they obtained their name signifying Island from the fact of an Island or Islet being surrounded by Water?

See the note on the word "Aytes," in JEsse's Gleanings in Natural History, second series, p. 88.

\section{X. \\ "A Vulgar Error."}

Some persons, who do not remember the difficulty which often exists on board ship of raising a plentiful supply of water from the sea to extinguish a fire in the vessel, jump to the strange conclusion that sea water will not act as fresh water does, in arresting the flames. The reason they give for this opinion is, that ships are so often burnt to the water's edge; this, in truth, is a strong evidence against their theory, rather than a corroboration of it; for, why do the flames go out then, if sea water does not extinguish them? And again, are not ships burnt to the water's edge in rivers as well as at sea?

\section{XI.}

The Common Bug.

Some Insects are viviparous, and are born complete in all their parts, undergoing some modi- 
fications only as to colour and size. A lady told me that she once let drop some melted wax from a candle on a common Bug, that the animal immediately died, but not before it had given birth to twenty or thirty young.

\section{XII.}

Aristotelian Philosophers.

Some persons are yet to be found who believe in the doctrine of Spontaneous Generation. To such I would recommend a perusal of SHAw's Zoology, vol. 6. part 1. pp. 4 and 381.

\section{XIII.}

\section{A Protestant Dog.}

At High Meadow (Lord GAGE's, in Gloucestershire), there lived two old persons, man and wife, who took care of the house, \&c. They had a dog named "Prince." They were Roman Catholics, and attended a chapel of that persuasion, but "Prince" regularly went to the Church of England. Every Sunday morning he posted himself at the rear of the house upon some steps, and listened to the bells; and when he thought it was time to go, he trotted over the fields to the Parish 
Church. He was always very punctual, and when "Prince" was seen making his way thither, it was a sign to every body that it was time to follow.

\section{XIV. \\ A Canine Impostor.}

Miss Annesley, of Bletchingdon Park, has got a Scots Terrier, named " Pepper," who often exhibits those marks of sagacity and intelligence, for which that breed is especially famed. One Sunday, Miss Annesley was walking to church, whither "Pepper" was not allowed to acompany her; he however followed his mistress as fast as his short legs and long back would permit, but she got some way a-head of him before she reached a wicket through which the path to the church led. Upon looking back, she saw poor "Pepper" limping along very lame; she stopped to look, he came up appearing very melancholy over his calamity, until he arrived close to the wicket where his mistress was, he then turned on his back, held one paw up as if in pain; she looked at it, and then letting it go and rising from her stooping position, the Dog jumped on his feet again, shot past her through the wicket, and went as sound as 
ever! the lameness being only a ruse to gain time and opportunity to pass through the gate which was to shut him out. Is this Instinct? Was there not forethought and contrivance in this? Or, what is Instinct? Where does it begin, and Reason end?

\section{XV.}

Canine Disinterestedness.

Mr. M'ADam, of Bath, grandson of the celebrated surveyor, \&c. of roads, has got a favourite Poney and Dog; and these two individuals are, as may be imagined, very intimate friends. One day the Dog came in search of Mr. M'AdAM, and having found him, shewed evident signs that he had something to communicate; his looks, his gestures, his movements, were full of anxiety; and if men will only attend to these, and follow their canine companion, the latter will always be found able to explain his errand. Mr. M'Adam wisely permitted himself to be guided by his Dog, who took him to the stables, went into the Poney's stall, and standing on his hind legs, put his fore paws on the manger; he first looked in, and then looked at his master, and this he did several times. 
The manger was empty, and, upon inquiry, it was found that the Poney, being on the sick list, was to have a lower diet, and, consequently, when the other horses received their corn, he was omitted; the Dog perceiving this, and conceiving justice had not been done to his friend, went in search of their joint master and benefactor, and told his tale as above described.

\section{XVI.}

Instance of Memory in a Mare.

Beasts are very well treated, and regarded with kindness at Bletchingdon Park; and, as is usual in such cases, shew they do not forget their friends. Miss Annesley had taught her mare to paw when she came up to her as a token of recognition. The owner went to London for six weeks, or longer, and left the mare in the country. On her return, when the mare came to the door for her mistress to ride, she would not stand still near the stone steps used for mounting, but kept backing and fidgetting about. Miss Annesuey desired the Groom to let her have her head, and see what she wanted. The mare backed, and when she got her head abreast of her Lady's she raised her nose 
to her face, so as to invite her attention, and then began pawing as she had been taught to do. Her great desire having evidently been to shew she had not forgotten her mistress or her ways; and this being accomplished, she stood still while she was mounted.

\section{XVII.}

The Elephant knows his Native Language.

PuIny remarks of Elephants, that, amongst other evidences of sense which they give, "intellectus est illis sermonis patrii." An interesting proof of the truth of this occurred a few years ago: A friend of mine, who had resided at Ceylon, went to the London Zoological Gardens. There was at that time an Elephant, a native of Ceylon, belonging to the Society, in the Gardens; he at first took no particular notice of my friend, shewing him no more attention than he did to any of his other visitors; but when the poor animal heard himself addressed in the Cingalese tongue, he exhibited the most unequivocal signs of joy and pleasure; turning his trunk about, and caressing his new friend with all the delight of one who in " a strange land" welcomes the arival of another

Q 3 
from his native country. Another remark of the Roman Naturalist, relating to the good qualities of the Elephant, is, I fear, equally true, in all its parts, at this day: " immo vero (quae etiam in homine rara) probitas, prudentia, æquitas."

\section{CONCLUSION.}

I have now finished my Notes, and some may think it had been well had I kept them to myself. I presume not to give an opinion; yet, if I have been the means of affording amusement to but one individual, and have led him to look upon all we do, and all we have, and all we hope to have, as referable to Him who hath given us all things freely to enjoy, I shall not repent me that I have amused myself in noting down the subjects of these pages, and then transferred them to the press.

I am aware that this is a volume of trifles; but he who takes even the most cursory view of the objects in Nature which surround him, whether animate or inanimate, cannot help observing, that how much soever they may differ in their component parts, in figure, in structure, in dimensions, in the uses to which they are applicable, and in 
the improvements of which they are susceptible by artificial means, they are founded on laws which all tend either directly or remotely to the comfort, the welfare, and the happiness of every animal, from man to the most insignificant being that creeps on the surface of this earth. Should there, then, not be some fellow-feeling on our parts towards the brute creation, since the GOD of us all has shewn such tender care for all ?

We have one instance, and only one since the fall of man, recorded in Holy Writ, of an inferior animal being miraculously empowered to speak after the manner of men, and it was, alas! to reproach him for his cruelty. It is one of the sad symptoms of our fallen nature, that superstition, ignorance, fashion, thoughtlessness, and prejudice should so frequently combine to harden and steel our hearts against the claims of the brute creation upon our regard, our sympathy, and our protection!

As our hopes of salvation depend, not only upon Natural Religion, but also upon the Revealed Word of God, for their fulfilment; so does every animal that breathes claim protection from us-not simply by an appeal to the natural affections of 
men,- - but to that most powerful of all authorities, that only source of all good-the Revealed Word of God-that Book of all Books-The Bible.

Regretting, as every sober-minded Christian must, the too numerous instances, which are to be met with in these days, of a misguided fanaticism, and of a mawkish humanity often unintentionally productive of much cruelty, " by reason of which the way of truth is evil spoken of ;" and condemning, as every honest man must, that fearful crime of hypocrisy-" for what is the hope of the hypocrite, though he hath gained, when God taketh away his soul?" - yet it must nevertheless be highly satisfactory to all religious persons to perceive the time approaching, if not actually arrived, when religion shall no more be considered a thing apart from, or inconsistent with, the ordinary pursuits and occupations of society; but, on the contrary, as a necessary companion, entering into the ideas, directing the actions, and pervading the opinions of many men, who, a few years ago would have denounced such sentiments and motives as cant and methodism, because they themselves, either like Gallio, "cared for none of these things," or like Pilate, feared the multitude; and would, 
like him, have followed the dictates of their better judgment and conscience, if they could have done so at no sacrifice of popularity or self-interest. It is, I believe, generally acknowledged, that, of late, a great improvement has taken place in this respect; let us hope we are not deceived in this good opinion, for " happy are the people who are in such a case, yea, blessed are the people who have the LORD for their GOD." Well, indeed, would it it be if men would consider that upon each one, in his own person, depends the fate of his Native Land; and that he, indeed, is a true patriot, who, by resisting the temptations of vice and impiety, assists in emancipating his Country from the slavery of Satan, and in securing the protection and approbation of Heaven. As to his own individual happiness-he will find that Religion brings with it its own reward; she will stand by him in all vicissitudes, she will comfort him in his sorrows, soothe him in his sickness, and support him in his poverty, as well as enhance his pleasures, smile upon him in health, and guide him in his prosperity. All those other accidents and events which weaken or dissolve human friendships do not affect her, for with her, as with 
178 MISCELLANEOUS MEMORANDA.

the Great Being from whom she proceeds, and " with whom she has to do," " there is neither variableness nor shadow of turning ;" by making her the directing power in all our doings, "neither things present, nor things to come, nor height, nor depth, nor any other creature, shall be able to separate us from the love of GOD, which is in CHRIST JESUS our LORD."

THE END. 


\section{$I N D E X$.}

\section{A.}

Anecdotes of Dogs, 169, 170, 171 .

......... a Mare, 172 .

......... an Elephant, 173.

........ a French Sportsman, 72.

$\ldots \ldots \ldots$ relating to a $\mathrm{Bug}, 168$.

Annesley's, Arthur, Esq., New Invention, 17.

Ayton's, Mr., Improved Casting Net, 79.

Anglers, their dislike to Netters, 2.

...... Dr. Johnson's opinion of, 2.

$\ldots \ldots$ a tradition amongst, 163 .

Angling not a cruel sport, 2, 112 .

Analogy between parts of nets and certain portions of animal bodies, 17,61 .

..... between the young Netter and young Seaman, 147 .

Antiquity of Net-work, 7 .

Animals, cruelty to, 112 .

Art, Terms used in the Netting, 13.

Authenticity of the Gospel, 32, 56.

Accident which befel Sir W. Pepys, and how to prevent it, 74 .

Affection for their young in Ear.wigs, 166.

Aristotelian Philosophers, 169.

B.

Bug, curious circumstance relating to the, 108 .

Balls of 'Twine, how to use them, 138.

Ban River, Salmon Fishery on the, 138.

C.

Canopy, whence the word is derived, 9 .

Cork cutting, 143.

Corks for nets, 146. 


\section{D.}

Drag Net, many nets called by that name, 115 .

Diminish, how to the size of a net, 14 .

Dog, Anecdotes of 169, 170, 171.

Dialect of Gloucestershire, 143.

Dyeing, 58.

Dead Netting, what is meant by, 2.

Dutch fishermen, 138.

\section{E.}

Elephant's Tusk, specimen of one, 161 .

Elephant, anecdote of one, 173.

Ear-wig, notice of the, 164 .

"Eye, the Old," 167.

"Ennui," the word not wanted, 74.

F.

False meshes, how made, 42.

Fish at Hastings, phenomenon respecting, 158.

Fly, House, the notice of the, 7 .

Fire at Sea, 168.

Fire, Sir W. Pepys fell into the, 74 .

Foundations, 144 .

G.

God's care of his creatures, 161, 162.

Gloucestershire Dialect, 143.

Gate, convenient form of a netted, 142 .

\section{H.}

Hood Net, 143.

Horse, substance found in the stomach of a, 162 .

Hastings, phenomenon observed at, 158.

Hay Net, why so called, 128.

Hint to Jack Smith, 146.

Huts, floors of, 147.

Jacket, a new, to a Net, 50 .

I.

Joinings, how to make different kinds of, 46

Increase, how to the size of Nets, 13. 


\section{K.}

Kyan's Patent, 60.

Knot, how to make a useful, 24.

Kinds of Nets, different, 70.

Ladies' Caps, 133.

L.

..... Scarfs, 134 .

Lozenge, the Quincuncial, Sir T. Brown's Treatise on, 14.

Lubber's Hole, 147.

\section{M.}

Mending Nets, being able to exercise the art of, 31 .

........... James and John, sons of Zebedee, engaged in, 32 .

Models of Nets, 73 .

Mistakes, ludicrous, 135.

Machinery, Nets made by, 144 .

\section{N.}

Net, how to, 19.

Nets, our Saviour alludes to them, 10.

.... Casting, 75.

.... Cinque Port, 100.

.... Cleeching, 71 .

.... Cabbage, 52.

.... Carreau, 106.

.... Drag, 115.

.... Eel, 105.

.... Fowling, 80.

.... Game, 124.

.... Hay, 128.

.... Herring, 4, 102.

.... Hoop, 88 .

.... Hood, 87, 143.

.... Horn, 104.

... Horse, 125-127.

.... Landing, 52, 87.

.... Mackerel; 4, 102.

.... Minnow, 91.

.... Shrimp, 96 .

.... Stake, 98 . 
Nets, Salmon, 98, 115.

... Trim-tram, 96 .

.... Trawl, 92 .

... Trammel, 83.

... Tunnel, 122.

... White Bait, 117.

.... Bridling, 34 .

.... Joining, 46.

.... Leading, 77, 85 .

.... Floating, 85 .

.... Mending, 26.

.... Strengthening or bordering, 40 .

.... Oblong, 37 .

.... Round, $51,52$.

.... Square, 36 .

.... Chinese, 9.

.... Egyptian, 8.

.... Esquimaux, 131.

.... South Sea Islanders, 10, 110, 130.

.... Port Jackson, made at, 129.

Needles, how to fill, 15, 138.

Nature varying, 161,162 .

\section{O.}

O does not always stand for nothing, 135 .

\section{P.}

Pockets of Nets, 65, 66, 78.

Pepys, Sir W., Accident which befell, 74.

Pix, 105, 106.

Preserving Nets, 54.

Pitte, fil de, 139.

Pliny's character of the Elephant, 173.

Q.

Quincunx, Sir T. Brown's Treatise on the, 14, 63. ........ Meaning of the word, 14.

R.

Repairing Nets, 26, 55 .

Rope Walk at Portsmouth, 142. 
S.

Spools, different kinds, 14, 17, 145.

Sea Water, error respecting, 168 .

Spontaneous Generation, absurd notion of, still prevalent, 169.

Silk Nets, 145 .

Sore Fingers, 147.

T.

Tools and Terms used by Netters, 13 .

Tanning, 54 .

Trackschuyts, 141.

Thames River, 139.

Twine to be as fine as possible, 145 .

...... may be boiled, 147 .

Turbot too fresh, 145.

Tick, the, 157 .

Traditions, 163.

Transformation, Insect, 164.

\section{V.}

Vertebræ, unusual structure of, 151.

Valves of Nets, $66,88$.

Vulgar Error, 168.

\section{W.}

Writers on Nets, no English, 5.

.............. French, 2, 5 .

Wings of Nets, 92, 99, 105, 106.

Washing Nets, 55.

Wire-work Netting, 67.

"Waste not," \&c. 143. 


\section{ERRATA.}

Page 8, last line but one from the bottom, for tenissimis read tenuissimis.

18, last line, for Treatise read Traité.

48 , fourth line from the bottom, for under $D$, read, under $\mathbf{D}$ and $\mathbf{D}$; and, last line but one, for under $C$ and $D$, read under $\mathrm{D}$ and $\mathrm{D}$.

58, for Dying, read Dyeing.

105, third line from bottom, for pixs, read pixes.

106, tenth line from top, for Echiquer, read Echiquier. 

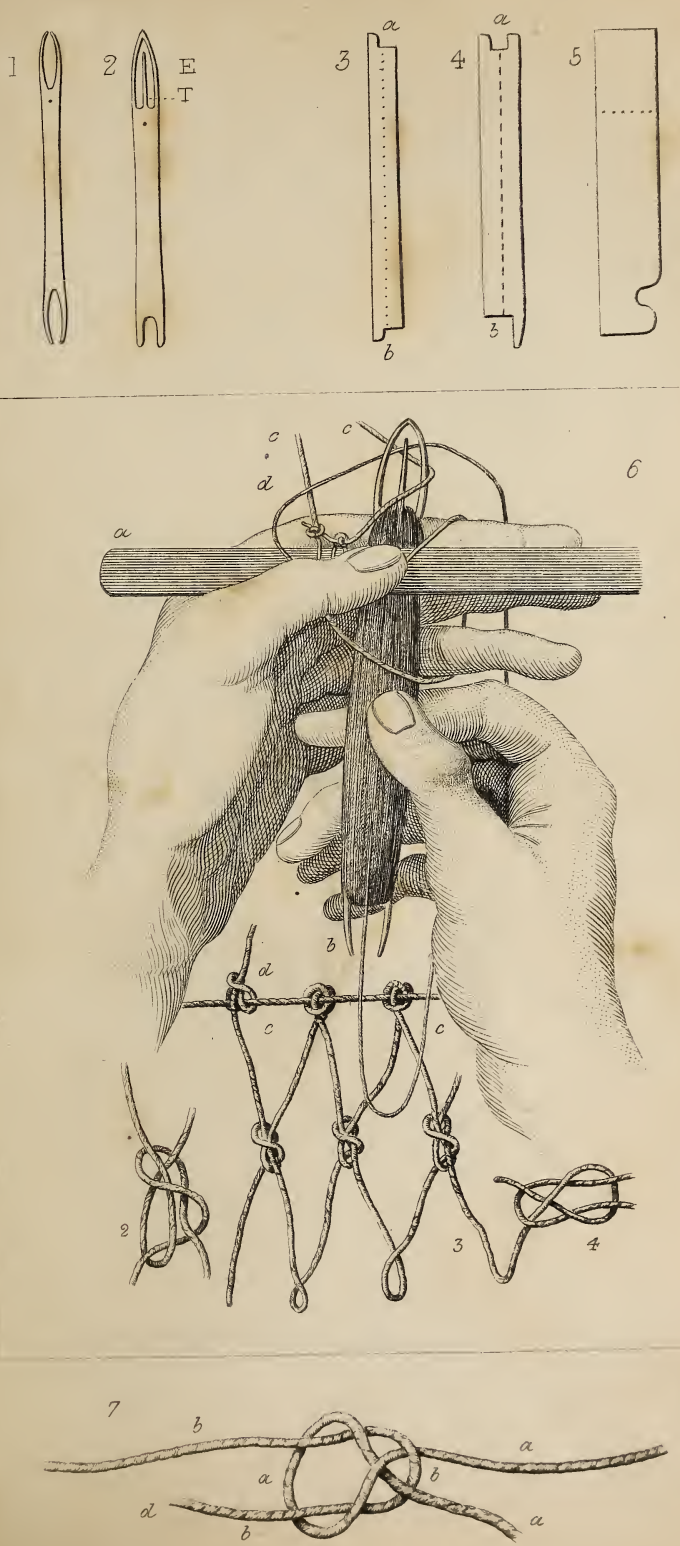

ig 12
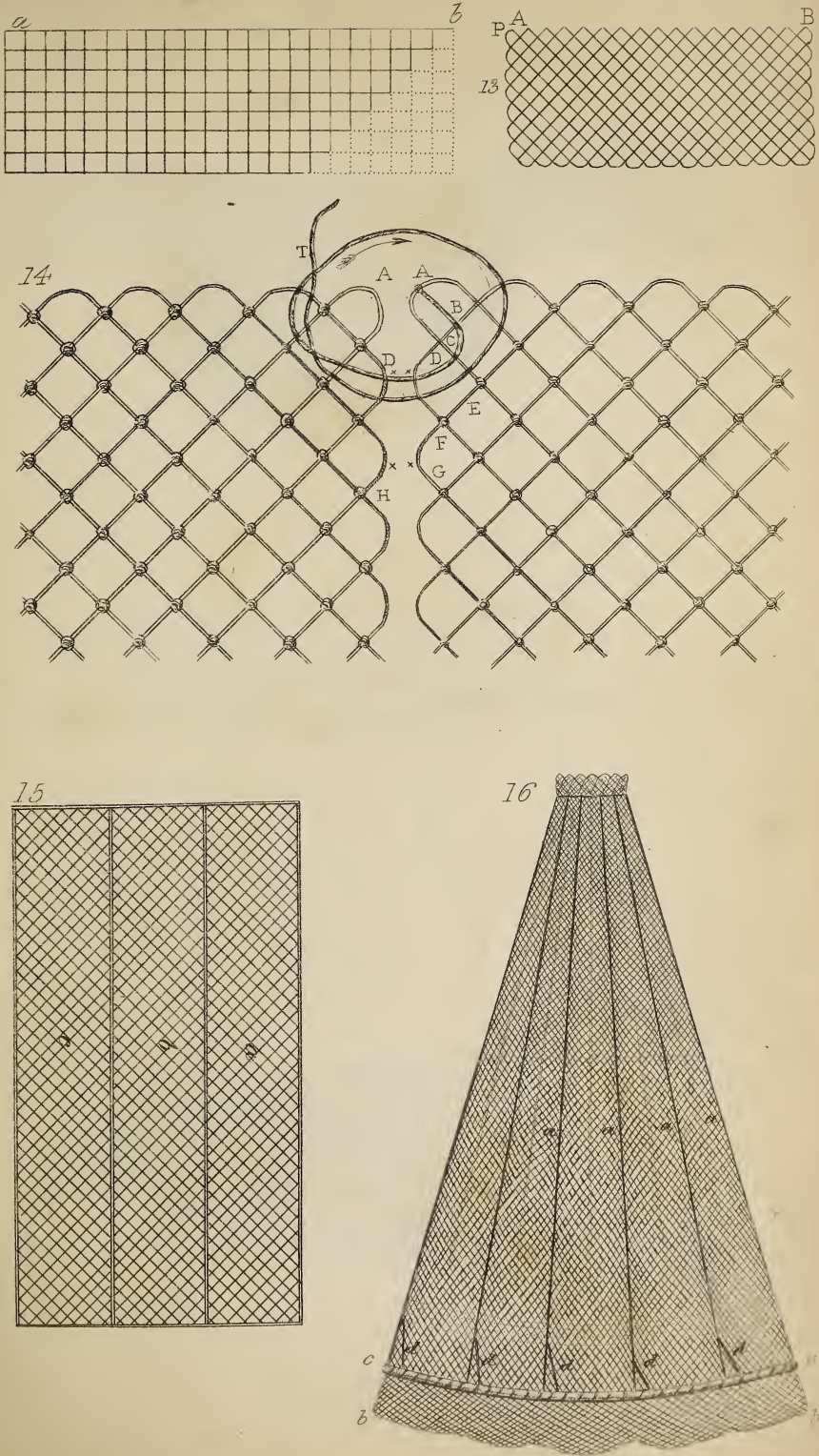

$a$

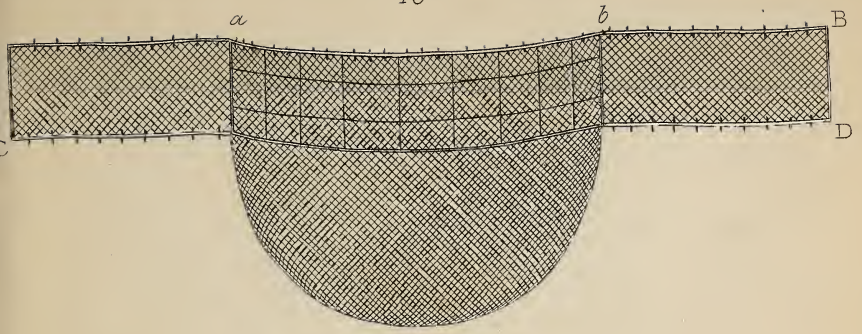

17
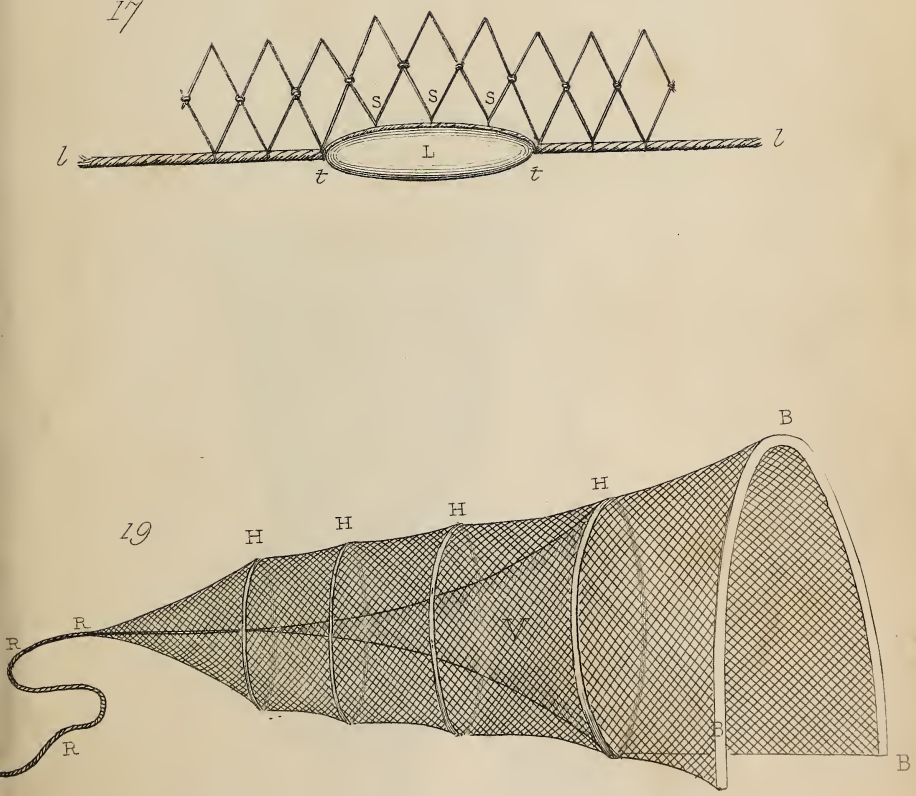

20

L
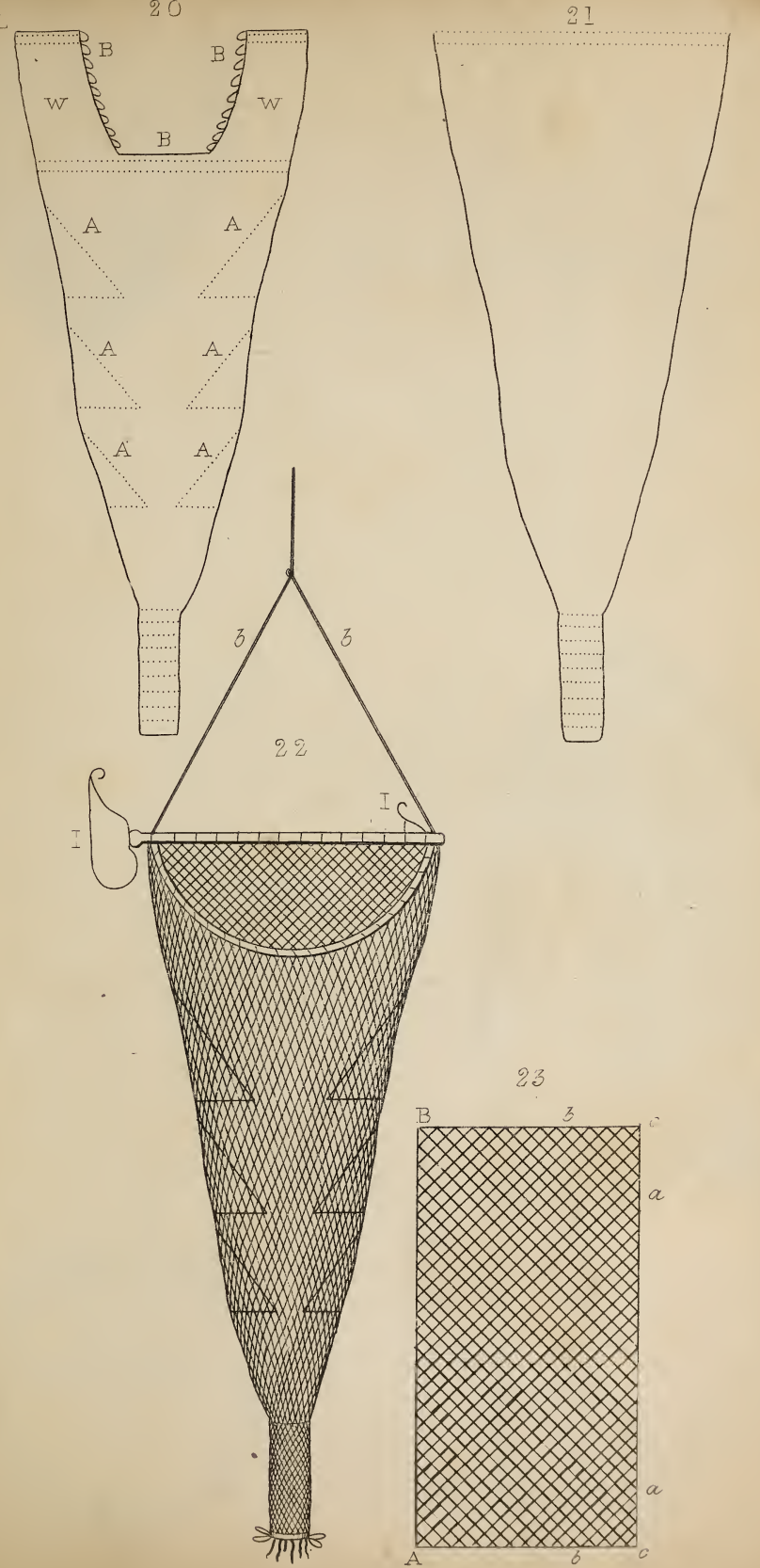




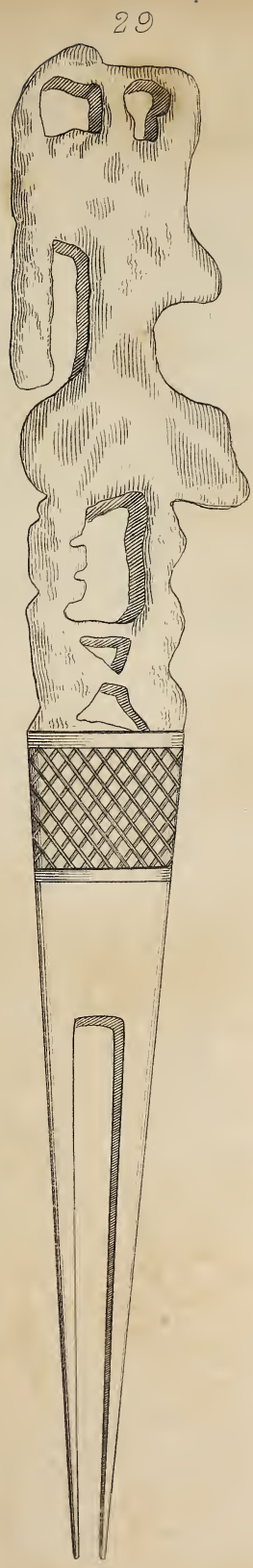



31
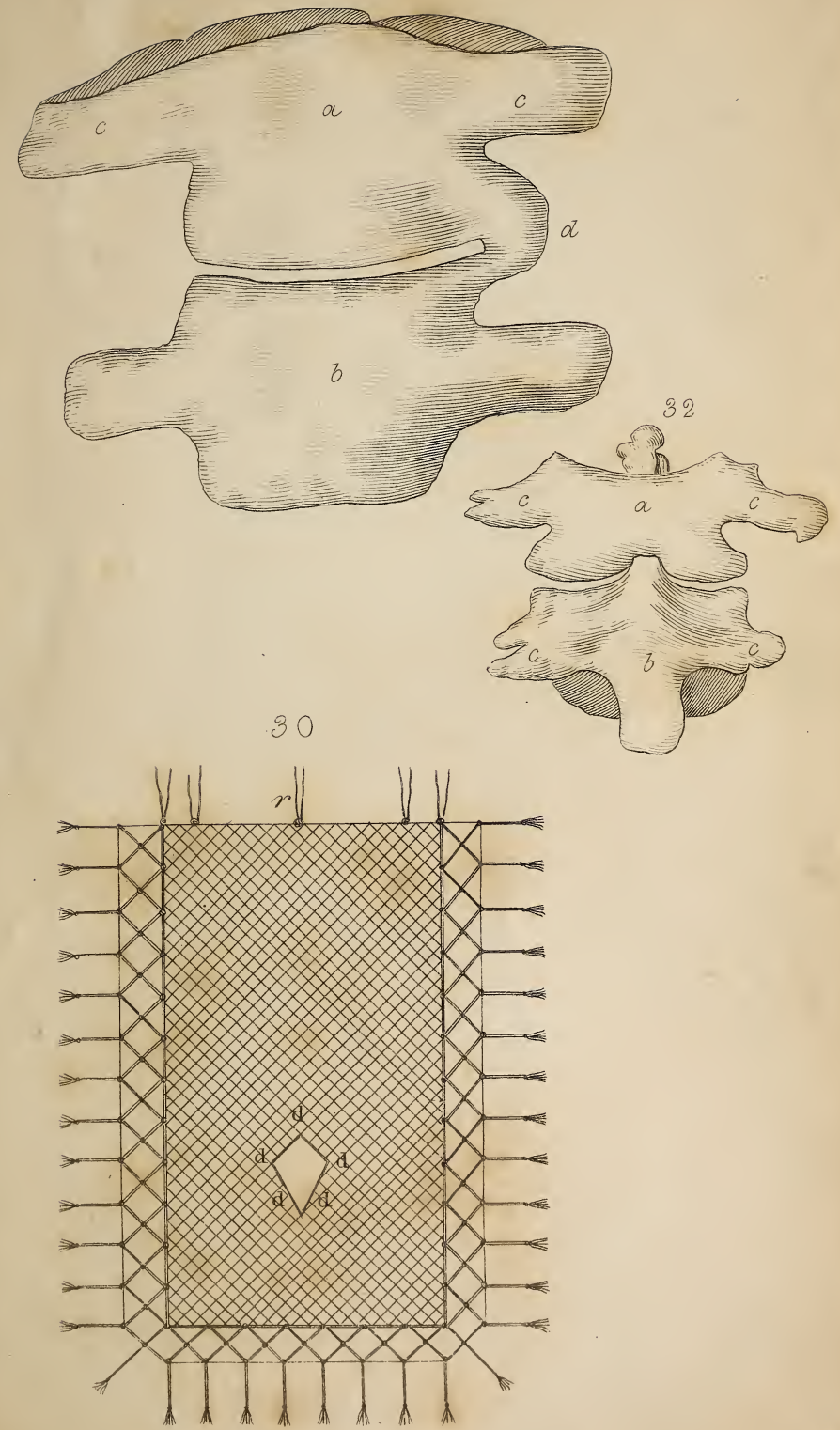





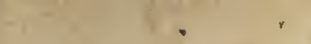


